\title{
Divertimento alrededor de la masonería en el cine
}

\section{Divertimento around Freemasonry in the cinema}

\author{
Rogelio Aragón \\ Universidad Iberoamericana, México \\ rogelio_aragon@hotmail.com
}

Recepción: 3 de octubre de 2018/Aceptación: 31 de octubre de 2018.

doi: https://doi.org/10.15517/rehmlac.v10i2.34761

Palabras clave

Representaciones sociales; cinematografía; teorías de conspiración; artes visuales; simbología.

Keywords

Social representations; cinematography; conspiracy theories; visual arts; symbology.

Resumen

A pesar de no siempre tener un papel protagónico, la masonería ha aparecido muchas veces en la pantalla grande. En ocasiones la vemos en forma de cameo, otras como un easter egg, pero Hollywood ha capitalizado el interés y el morbo que genera en el público esta organización con el fin de construir mejor a sus personajes o de complementar las historias narradas en sus filmes. En este vertiginoso periplo descubriremos algunas de las representaciones de la masonería y los masones que han aparecido en el cine reciente, además de los motivos -abiertos u ocultos- que justifican su presencia en la pantalla.

Abstract

Despite not always having a lead role, Freemasonry has appeared many times on the big screen. Sometimes we see it in the form of a cameo, sometimes as an Easter egg, but Hollywood has capitalized on the interest and curiosity that this organization generates in the public and in order to improve the building of its characters or complement the stories told in its films. In this fast-paced journey, we will discover some of the representations of Freemasonry and Freemasons that have appeared in recent cinema, as well as the motifs -open or hiddenthat justify their presence on the screen.

\section{¡Masonería!}

Quien escucha esta palabra muestra, casi indudablemente, algún tipo de reacción. Para los expertos en el tema -o quienes creen serlo-, ya sea desde la academia, la propia masonería o desde el diletantismo, oír cualquier mención a esta organización les pone en alerta: ¿Se acercarán a un nuevo aspecto de la fraternidad, antes desconocido? ¿Percibirán alguna opinión relevante? ¿Será -acaso- que alguien leyó sus artículos o publicaciones?

Para el público en general -que no es experto en la materia, pero que ha escuchado toda clase de opiniones sobre esta realidad, tanto a favor como en contra- enterarse de temas masónicos también genera interés: ¿La masonería es una religión? ¿Es cierto que los masones dominan el mundo? ¿Están iniciados los políticos y empresarios más importantes y poderosos? ¿Es cierto que sus rituales son de corte satánico? 
La industria cinematográfica, en específico Hollywood -llamémoslo así para diferenciar al cine de los grandes estudios, enormes presupuestos y distribución internacional de aquellas producciones independientes, locales y de comercialización limitada-, es consciente de esta fascinación por la masonería. Por tanto, la ha explotado para su beneficio. Sin embargo, y al parecer, rodar superproducciones centradas exclusivamente en el tema de la masonería no es rentable, dado que - a excepción de un largometraje del que hablaré en su momento- no hay un solo filme en la historia reciente que gire enteramente en torno a la masonería. anterior? $^{1}$

Entonces, ¿dónde radica la explotación del tema masónico, mencionada en el párrafo

Antes de continuar, debo hacer una pequeña nota aclaratoria: a pesar de que muchos de los filmes de los que hablaré cuentan con títulos en español, preferiré conservarlos en su idioma original. No es por alguna preferencia arbitraria, sino para evitar confusiones dado que, dependiendo del mercado en el que fueron distribuidos, cuentan con títulos diferentes en castellano. Así, por ejemplo, la película Prisoners, dirigida por Denis Villeneuve y protagonizada por Hugh Jackman, se estrenó en España como Prisioneros, mientras que en algunos lugares de Hispanoamérica se llamó La sospecha y -en otros-Intriga. Asimismo, me referiré únicamente a producciones hollywoodenses recientes, por lo que filmes como L'âge d'or, El ángel exterminador, Forces occultes y las dos versiones de Are you a Mason? no estarán analizadas en las siguientes páginas. Tampoco incluiré The Man Who Would Be King, debido a que amerita un estudio más profundo y contrastado con su material fuente, la novela homónima de Rudyard Kipling. También quedarán fuera de las siguientes páginas la serie de películas basadas en los libros de Dan Brown, dado que requieren pruebas cruzadas con sus contrapartes literarias.

La función principal de cualquier película, por encima de los calificativos con los que podamos describirla, es narrar una historia ${ }^{2}$. La forma en la que se lleva a cabo esta acción

\footnotetext{
${ }^{1}$ En la obra del filósofo Martin Heidegger no hay apartados o capítulos dedicados exclusivamente al cine. Sin embargo, se muestra crítico del medio al concebirlo como una extensión de la forma de revelar entidades dentro del marco (das Gestell) tecnológico producido por la modernidad, es decir, aquello que es no-tecnológico pero que se encuentra dentro del marco de lo tecnológico y que, más que una forma de clasificación u ordenamiento, pretende abarcar activamente todo lo que tiene presencia en el mundo, lo que convierte a los seres en recursos para ser explotados en detrimento del Ser. Un interesante argumento en sentido opuesto -que afirma que la crítica de Heidegger al cine no es por su naturaleza tecnológica sino por pretender ser una "copia transparente del mundo" - se encuentra en Michael Josiah Mosley, "Another look at Heideggerian Cinema: cinematic excess, Antonioni's Dead Time and the film-photographic image as copy", Film-Philosophy 22, no. 3, (octubre 2018): 364-383, https://www.euppublishing.com/doi/full/10.3366/film.2018.0085

Una obra que gira en torno a las formas en que la industria cinematográfica en su conjunto ha explotado los síntomas/fetiches de la sociedad, entendidos los primeros como "la excepción que perturba la superficie de la falsa apariencia" y los segundos como "la encarnación de la mentira que nos permite soportar la inaguantable verdad”, es el texto clásico de Slavoj Žižek Enjoy your Symptom! (Nueva York: Routledge, 2008).

${ }^{2}$ Algunos especialistas argumentarán que la función de un filme es la representación artística de una realidad y que escribir sobre cine es traducir al idioma escrito algo que ya se tradujo del idioma escrito al idioma visual.
} 
es prácticamente infinita: cada director opta por la que considera que es la mejor manera de comunicar su idea al público. Sin embargo, y pecando de un reduccionismo casi extremo, se puede decir que la narrativa en el cine es una concatenación de causas y efectos que se desarrollan en el espacio y en el tiempo. Dicha cadena de acciones, junto con sus causas y efectos, forman la trama de la película. Y dentro de este argumento se incluyen también los elementos diegéticos y no-diegéticos ${ }^{3}$, cuya diferenciación radica en si los mismos son percibidos por los personajes de la película o no lo son. Por lo general ambos tipos de elementos se analizan a partir de los sonidos que se incluyen en el filme, aunque yo añadiría otra categoría a la que me referiré más adelante.

Para dejar en claro cuáles son los elementos diegéticos y no-diegéticos dentro de la clasificación de «sonido», pensemos en tres de las escenas más famosas de la historia del cine: el vuelo espacial del doctor Heywood Floyd en 2001: a Space Odyssey, la persecución en coche de Bullitt y la carrera de entrenamiento de Rocky Balboa en Rocky II. En el primer caso, el director Stanley Kubrick decide omitir por completo los fundamentos sonoros diegéticos y, dado que la acción transcurre en el espacio estelar y en el interior de un vuelo comercial totalmente vacío que se dirige a una estación espacial, los espectadores imaginamos que la escena transcurre en absoluto silencio para los personajes. Ninguno de ellos -ni los pilotos, ni los sobrecargos y, ni siquiera, Heywood Floyd-escuchan el Danubio Azul de Johann Strauss con el que Kubrick decidió substituir - de cara al espectador- el «sonido» del vacío del espacio estelar. En el segundo ejemplo, el director Peter Yates acompaña la escena anterior a la persecución en coche por las calles de San Francisco con la música que Lalo Schifrin compuso para su largometraje. Pero, en cuanto Steve McQueen pisa el acelerador de su Mustang para perseguir a los criminales, el sonido no-diegético se substituye abruptamente por el diegético. Así, tanto personajes como audiencia escuchamos el rugido de los motores y el chirriar de los neumáticos. Durante el lapso que dura la escena, estamos intermitentemente en el interior del auto del protagonista y en el de los mafiosos a los que persigue, rodeados por completo de los sonidos que emiten sus respectivos automóviles. Por último, Sylvester Stallone -quien actuó y dirigió Rocky II- mezcla los sonidos diegéticos con los no-diegéticos en una de las escenas más memorables del filme. En cuanto el boxeador Rocky Balboa pone un pie fuera de su casa se escuchan las primeras notas de Gonna Fly Now, parte de la banda sonora compuesta por Bill Conti para la película. La música no-diegética de Conti acompaña a Rocky mientras corre por las calles de Filadelfia como parte de su entrenamiento, entremezclada con los sonidos diegéticos de las personas

Allan Casebier, Film and Phenomenology: toward a realist theory of cinematic representation (Cambridge: Cambridge University Press, 1991).

${ }^{3}$ Ben Winters, experto en teoría cinematográfica, propone que el sonido de un filme debería considerarse intradiegético, como si se tratara de un narrador, dada su importancia en la construcción de la narrativa y el énfasis que pone en la calidad "irreal" del cine. Ben Winters, "The Non-Diegetic Fallacy: film, music and narrative space", Music and Letters 91, no. 2, (mayo 2010): 224-244, https://doi.org/10.1093/ml/gcq019 
que saludan al boxeador a su paso y los gritos y risas del gran número de niños que se unen a él durante su carrera. Así, el espectador tiene un panorama acústico completo de la escena, lo que en mi opinión le confiere esa calidad de clásica del cine hollywoodense contemporáneo.

\section{Episodio 1: Los ángeles y los demonios}

En el caso que nos ocupa, el de la masonería en el cine, nos encontramos ante dos escenarios que ponen en entredicho las categorías tradicionales de elementos diegéticos y nodiegéticos. En el primer escenario, la masonería no forma parte ni de la trama ni de la historia de las películas, y su inclusión -ya sea verbal o visual-es tan fugaz e irrelevante que podría calificarse como easter eggs: elementos ajenos al desarrollo del filme que se insertan en éste únicamente para que el público los note y hable de ellos, como una herramienta de la estrategia de mercadotecnia y promoción de la película.

Así, por ejemplo, en la película Sabotage (2014), protagonizada por Arnold Schwarzenegger, durante una redada en una casa de seguridad de unos narcotraficantes, se ve en una pared una reproducción de la pintura Never Alone, de tema masónico. En Bad Boys 2 (2003), estelarizada por Will Smith, los dos policías protagonistas de la historia toman un camión de carga para perseguir a los criminales. En su portón trasero se aprecia una pegatina con una escuadra y un compás. Además, en producciones como Arachnophobia (1990), Overboard (1987), Back to the Future (1985), The Best of Times (1986) y Wayne's World (1992) hay escenas en las que se muestran los letreros de bienvenida a distintas poblaciones pequeñas de Estados Unidos. Y, en ellos, se anuncian los clubes y asociaciones presentes en dichas localidades: Rotarios, Club de Leones, Kiwanis y, por supuesto, los masones. En otras obras, como Erin Brokovich (2000) y Miami Vice (2006), en ciertas escenas aparecen los exteriores de edificios masónicos sin que los mismos tengan ninguna relevancia para la acción de la película. Un ejemplo reciente y vigente -en el momento de escribir estas líneas la película todavía se hallaba en exhibición comercial- es la secuencia inicial de Bohemian Rhapsody (2018), del director Bryan Singer, que relata el ascenso a la fama del legendario cantante Freddie Mercury y de la banda de rock Queen. En una escena vemos un acercamiento a las manos de un anónimo roadie, que está preparando el escenario para la presentación de Queen en el concierto de Live Aid. En su dedo anular derecho lleva un anillo masónico, que es totalmente ajeno a la trama y la historia, pero que ya ha despertado la especulación entre un sector de la audiencia en diversos foros de internet. 


\section{Imagen 1}

Arnold Schwarzenegger pasa frente a un cartel masónico en Sabotage

Fuente: Página web de la Gran Logia de la Columbia Británica y Yukón, http://freemasonry.bcy.ca/fiction/images/sabotage.html

\section{Imagen 2}

Los protagonistas de Miami Vice estacionan su coche frente a un templo masónico

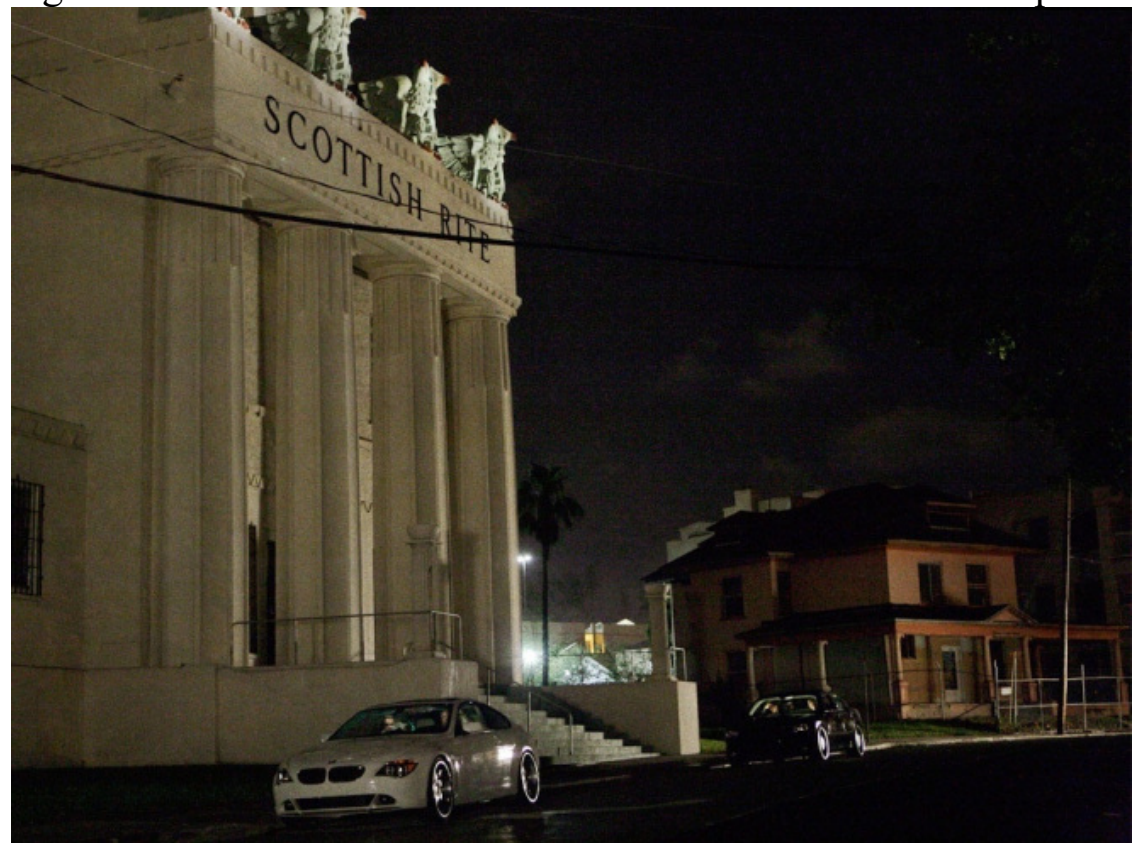

Fuente: Excuses and Half Truths, "Encounters and deprtures: Miami Vice", https://excusesandhalftruths.com/2015/07/01/encounters-and-departures-miami-vice/ 


\section{Imagen 2-2}

Un roadie prepara el escenario para un concierto de Queen en Bohemian Rhapsody

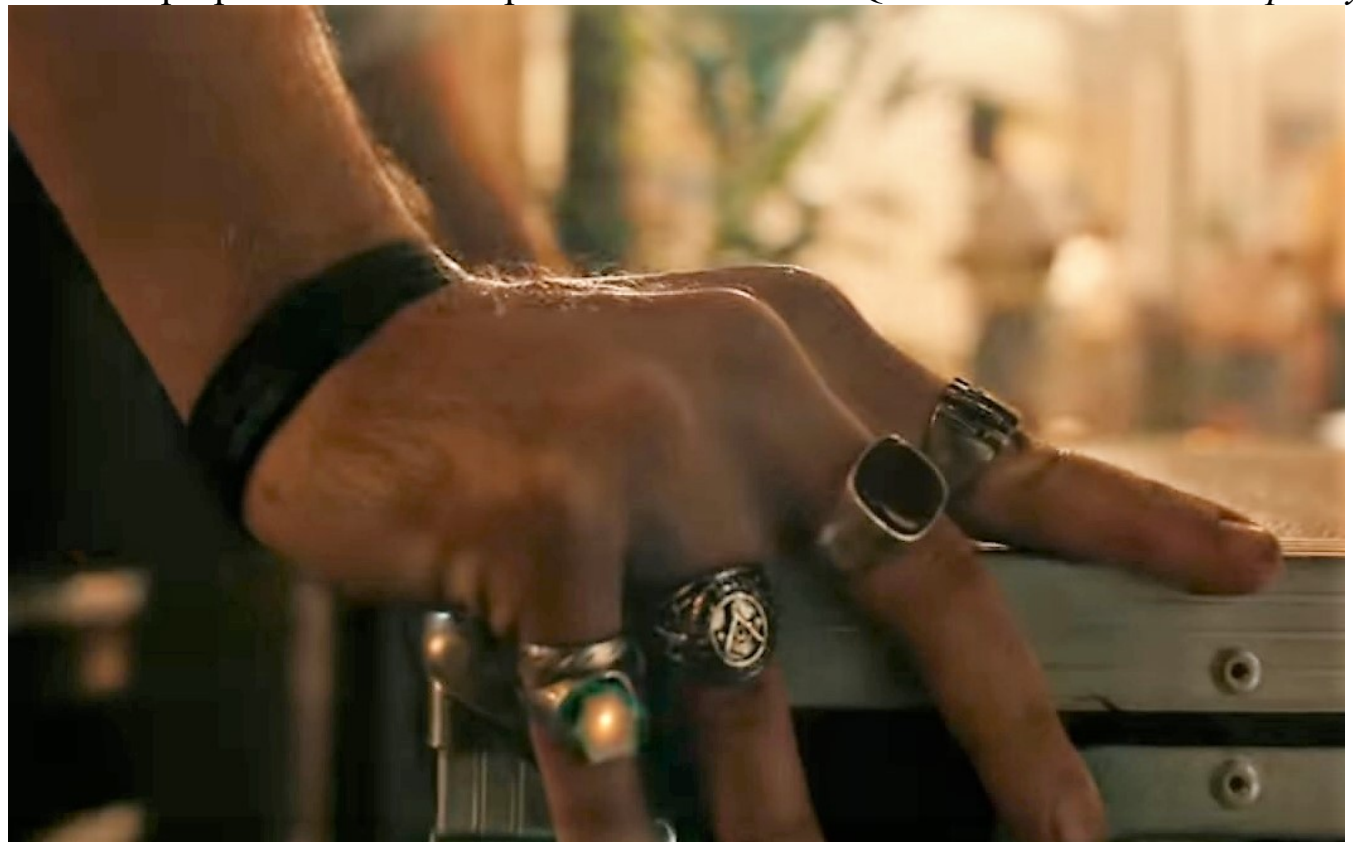

Fuente: Reddit, r/conspiracy, "Bohemian Rhapsody: why the freemasonic symbolism?", https://www.reddit.com/r/conspiracy/comments/9sfa0t/bohemian rhapsody why the freemasonic symbolis $\underline{\mathrm{m} /}$

En el segundo escenario están las menciones - orales o visuales- a la masonería que no tienen relación con la trama pero sí con la historia. Estas alusiones tienen, la mayoría de las veces, la intención de construir mejor a algún personaje y dar al público mayores pistas sobre sus orígenes, carácter o intenciones. En este apartado es notorio el tratamiento maniqueo del tema: los personajes a los que se atribuye pertenencia a la masonería o son del bando de los «buenos» o son «villanos». No hay término medio. Así, en la ya mencionada película Prisoners (2013), el detective Loki, interpretado por Jake Gyllenhaal, es el arquetípico policía de exterior rudo y austero, dedicado a su trabajo en cuerpo y alma, aparentemente sin familia ni amigos y que hace lo imposible para resolver el caso. Lo único que sabemos de él es que es masón. Y lo conocemos por el anillo que trae siempre puesto, en el que se distinguen la escuadra y el compás. 
Imagen 3

Jake Gyllenhaal en Prisoners

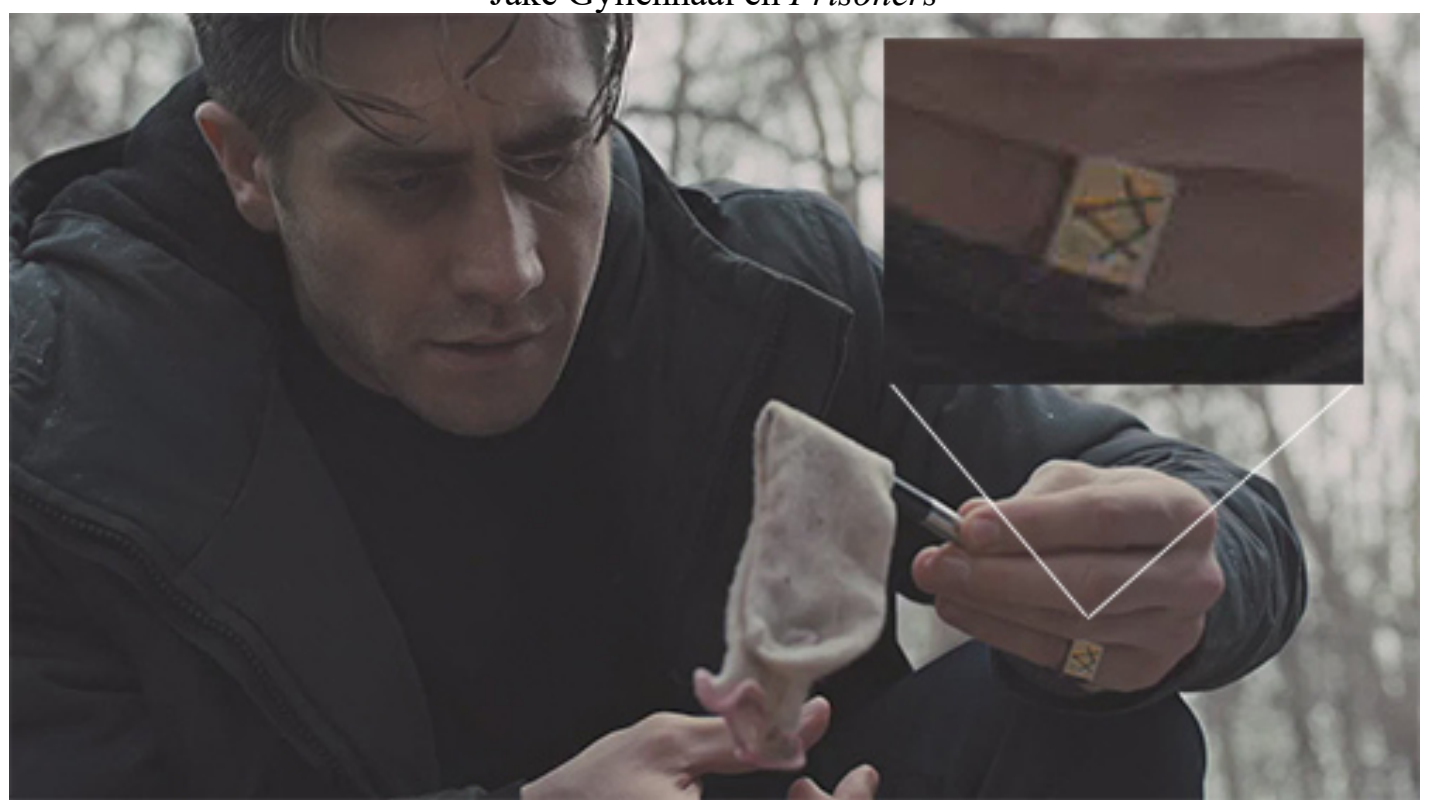

Fuente: Vigilant Citizen, "Esoteric meaning and symbolism in the movie Prisoners", https://vigilantcitizen.com/moviesandtv/esoteric-meaning-movie-prisoners/

Otro personaje -rudo pero «bueno»-que porta un anillo masónico es el sargento Al Apone, en la película Aliens (1986), interpretado por el actor Al Matthews. La acción de Aliens se desarrolla en el siglo XXII, por lo que al parecer se augura que la masonería seguirá vigente -al menos- otro siglo más. Eso o que el actor Al Matthews - en su vida cotidiana- es miembro de dicha hermandad, dado que en otro papel que desempeñó para la película The Apocalypse Watch (1997) -donde daba vida a un agente de la CIA, es decir a otro de los «buenos»-se le ve llevando el mismo anillo.

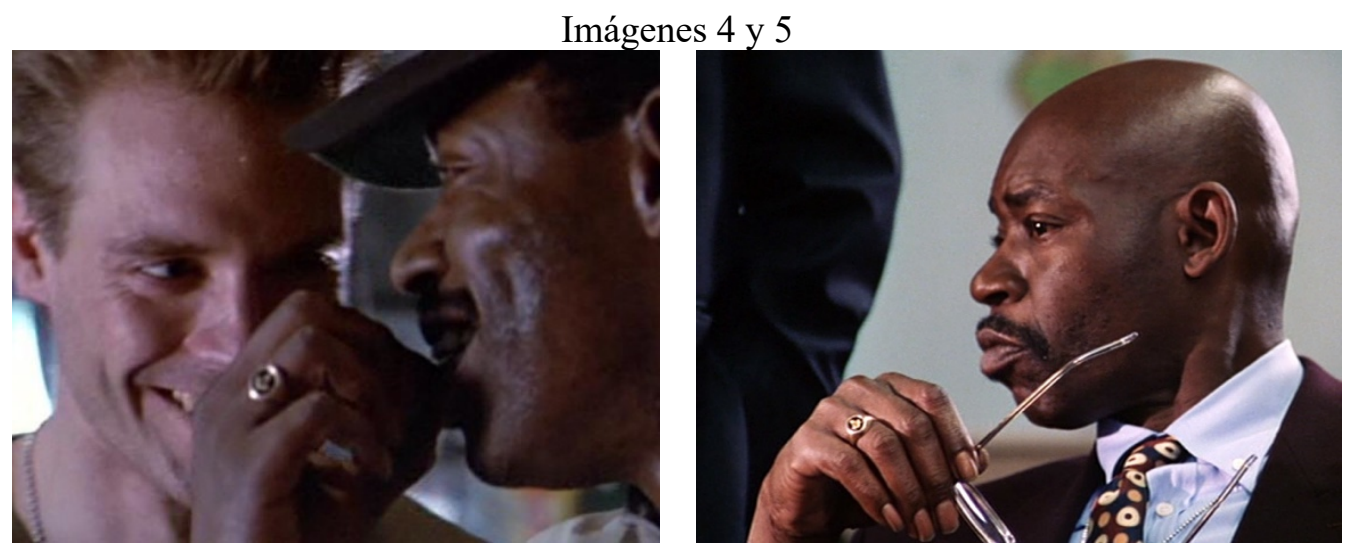

Arriba: el actor Al Matthews en Aliens. Abajo: Al Matthews en The Apocalypse Watch. Fuentes: The winding Stairs, "Freemasonry in movies and tv", https://www.thewindingstairs.com/blog/2015/10/09/freemasonry-inthe-movies-and-tv/ Página web de la Gran Logia de la Columbia Británica y Yukón, http://freemasonry.bcy.ca/fiction/images/apocalypse_watch.html 
En American Gangster (2007) uno de los pocos policías neoyorquinos que no es corrupto, el capitán Lou Toback, lleva en la solapa de su chaquetón un distintivo masónico. Otro policía recto y limpio - que siempre usa su anillo masónico y que es capaz de investigar y arrestar a su propio hijo cuando éste se involucra con narcotraficantes rusos- es Burt Grusinsky -encarnado por el gran Robert Duval- en We Own The Night (2007). En Lonely Hearts (2006) el héroe de la historia, el detective Elmer Robinson (John Travolta), porta también un anillo con símbolos masónicos. De hecho, este filme está basado en la historia real del abuelo del director y guionista Todd Robinson, un policía que a finales de los años 40 logró capturar a una dupla de asesinos seriales responsables de la muerte de una veintena de mujeres. Fuera del mundo de la justicia y el combate al crimen, encontramos un personaje que no es necesariamente «bueno» pero que despierta simpatía. En la película de dibujos animados The Ant Bully (2006), la abuela del personaje principal -que es una ferviente adepta de teorías de conspiración, extraterrestres y personajes míticos, como Pie Grande- tiene una silla mecedora con una escuadra y un compás grabados en el respaldo.

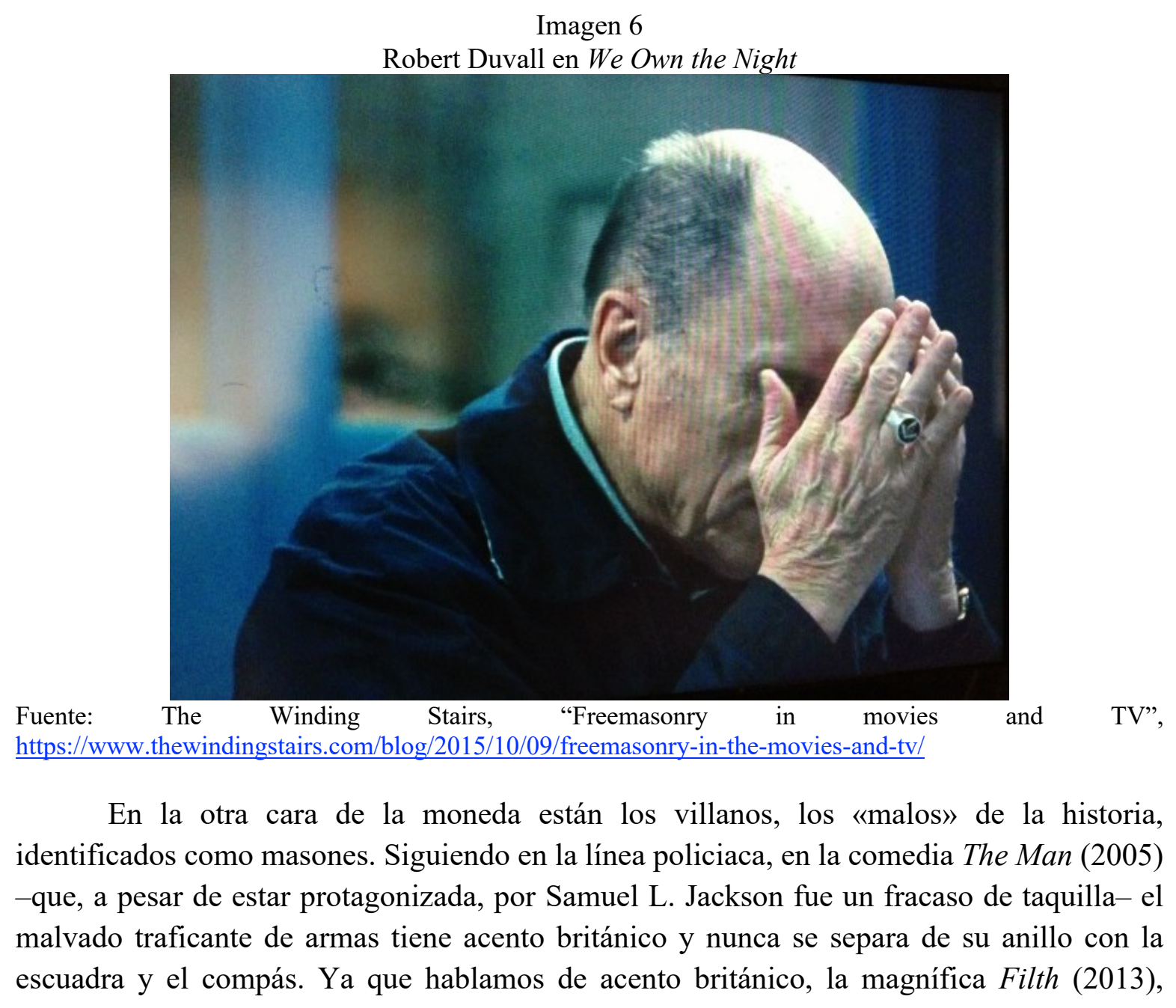


dirigida por Jon S. Baird, con una excelente actuación de James McAvoy en el papel protagónico y basada en un libro de Irvine Welsh, relata la historia del detective Bruce Robertson, un corrupto policía edimburgués, alcohólico y farmacodependiente, que busca a toda costa hacerse del puesto de jefe de detectives, que no tiene el más mínimo escrúpulo y que se sirve de la extorsión y la violencia para satisfacer sus más bajas pasiones. Robertson es masón, al igual que su jefe -al que intenta reemplazar-y que su único amigo, el tranquilo y entrañable contador Clifford Blades. En una escena, Robertson consigue cocaína durante una reunión de su logia, así que no es el único masón «villano» de esta historia.

Imagen 7

Los personajes Bruce Robertson (centro) y Clifford Blades asisten a su logia masónica en Filth

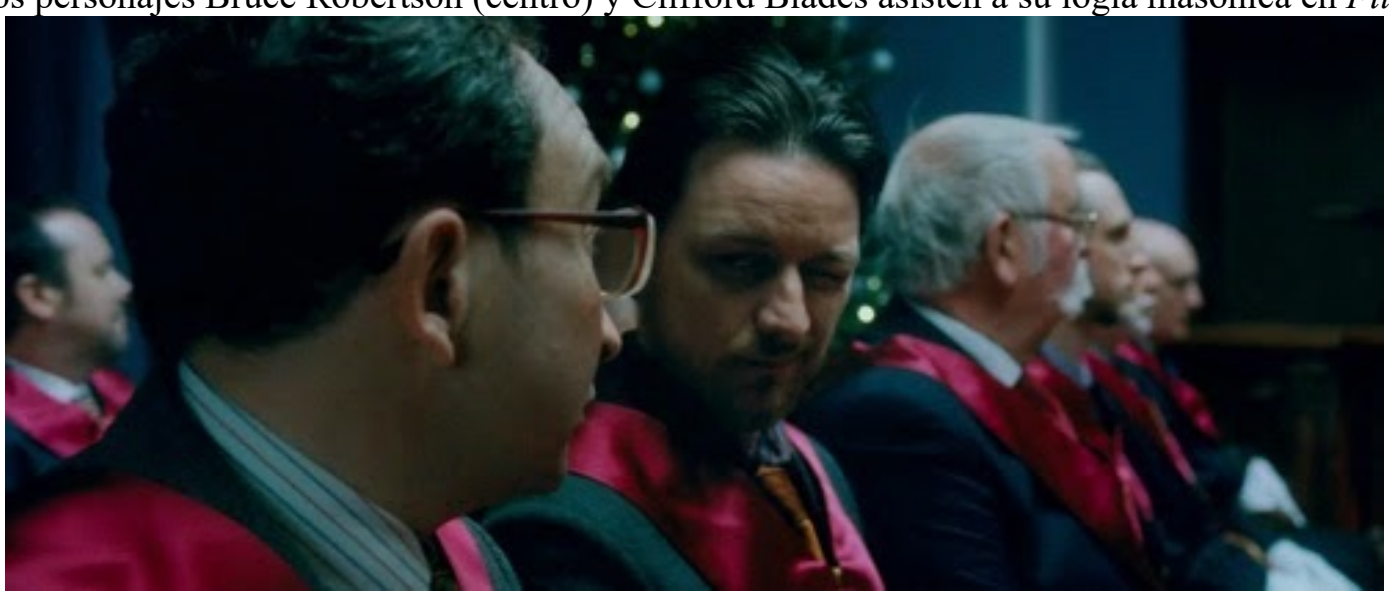

Fuente: Now in Full Color, "There's something seriously wrong with me", http://www.nowinfullcolor.com/2014/03/theres-something-seriously-wrong-with-me.html

Otro policía corrupto que lleva un distintivo masónico es Charlie Wade, interpretado por Kris Kristofferson en la película Lone Star (1996) de John Sayles. En un momento dado, Wade está con unos personajes que le darán un soborno en un restaurante mexicano. La escena se corta en un primer plano de la mano de Wade sacando de entre unas tortillas un fajo de billetes. En uno de sus dedos se observa un anillo con una escuadra y un compás. Asimismo, un personaje antipático, corrupto y sin escrúpulos, pero ajeno al ámbito policiaco, es el millonario Wade Gustafson, del excepcional filme Fargo (1996) de los hermanos Coen. Durante una toma, se aprecia fugazmente un anillo masónico en uno de los dedos de Gustafson. Otro masón que no es enteramente «malo» en estricto sentido, pero sí es un personaje antipático, es el ambicioso y manipulador productor de televisión Mark Heiss, caracterizado por Christopher Walken, en la película Domino (2005) de Tony Scott. 


\section{Imagen 8}

El corrupto Charlie Wade mete la mano en las tortillas

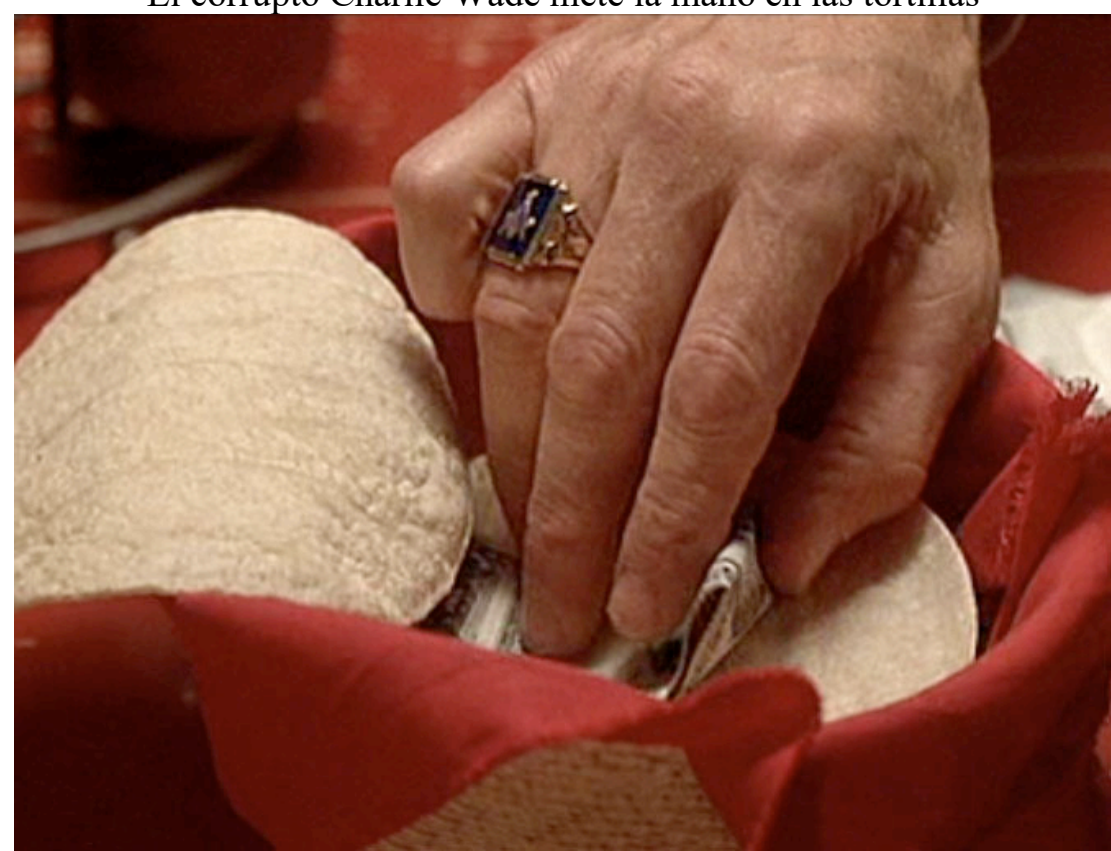

Fuente: Página web de la Gran Logia de la Columbia Británica y Yukón, http://freemasonry.bcy.ca/fiction/images/lone_star.html

\section{Imagen 9}

\section{Christopher Walken interpreta a Mark Heissen Domino}

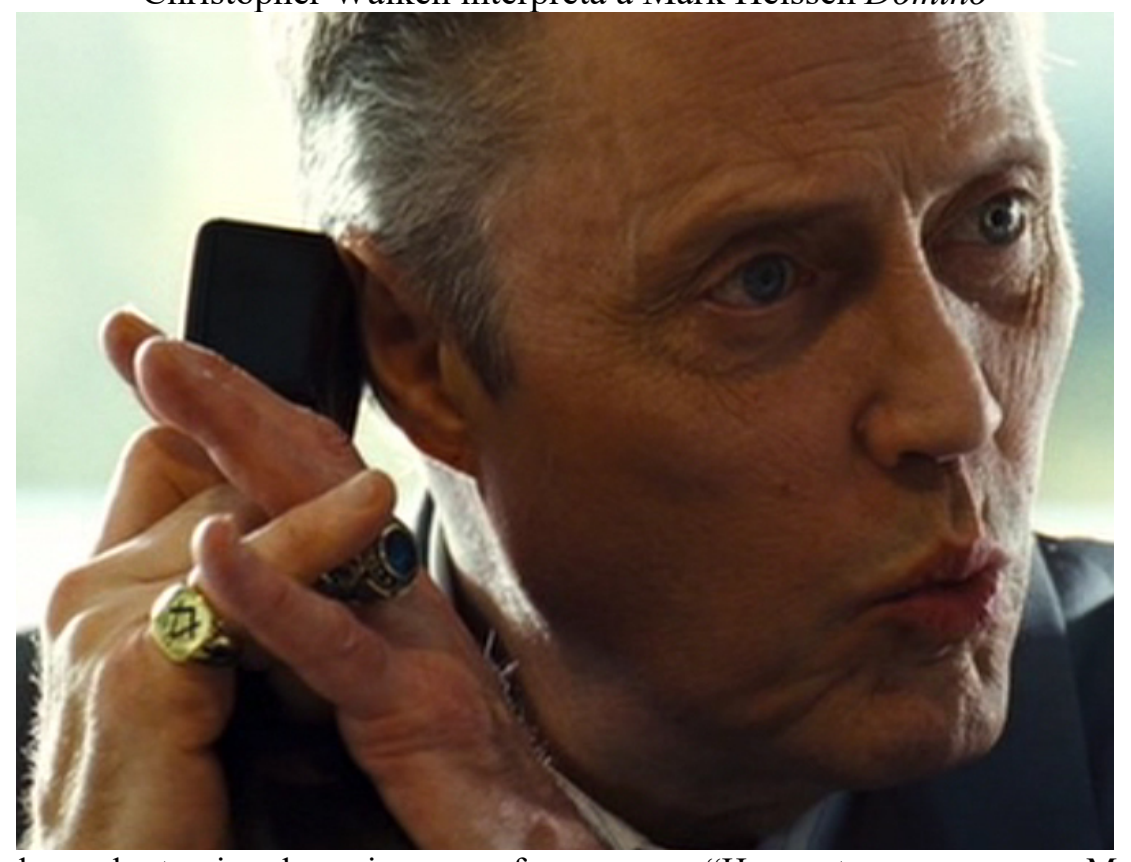

Fuente: Jewelry: best jewelry images for you, "How to wear a Masonic ring", http://www.yarss.com/rings/Wearing-Masonic-Rings30yrqswoza/ 
En el mundo de la fantasía también es posible encontrar a «malos» asociados con la masonería, gracias al trabajo de los diseñadores de producción y vestuario. Así, en Mad Max 3: Beyond the Thunderdome (1985) el doctor Dealgood, que es a la vez juez, subastador, maestro de ceremonias y máxima autoridad en el postapocalíptico pueblo de Bartertown, lleva como vestuario cotidiano una toga de magistrado y una enorme insignia masónica colgada de una gruesa cadena de oro alrededor del cuello. Dicha insignia -que, para variar, se trata de una escuadra y un compás- es más visible cuando funge como maestro de ceremonias en los combates a muerte organizados en el Thunderdome, una especie de coliseo romano del futuro distópico.

Imagen 10

El doctor Dealgood en Mad Max 3

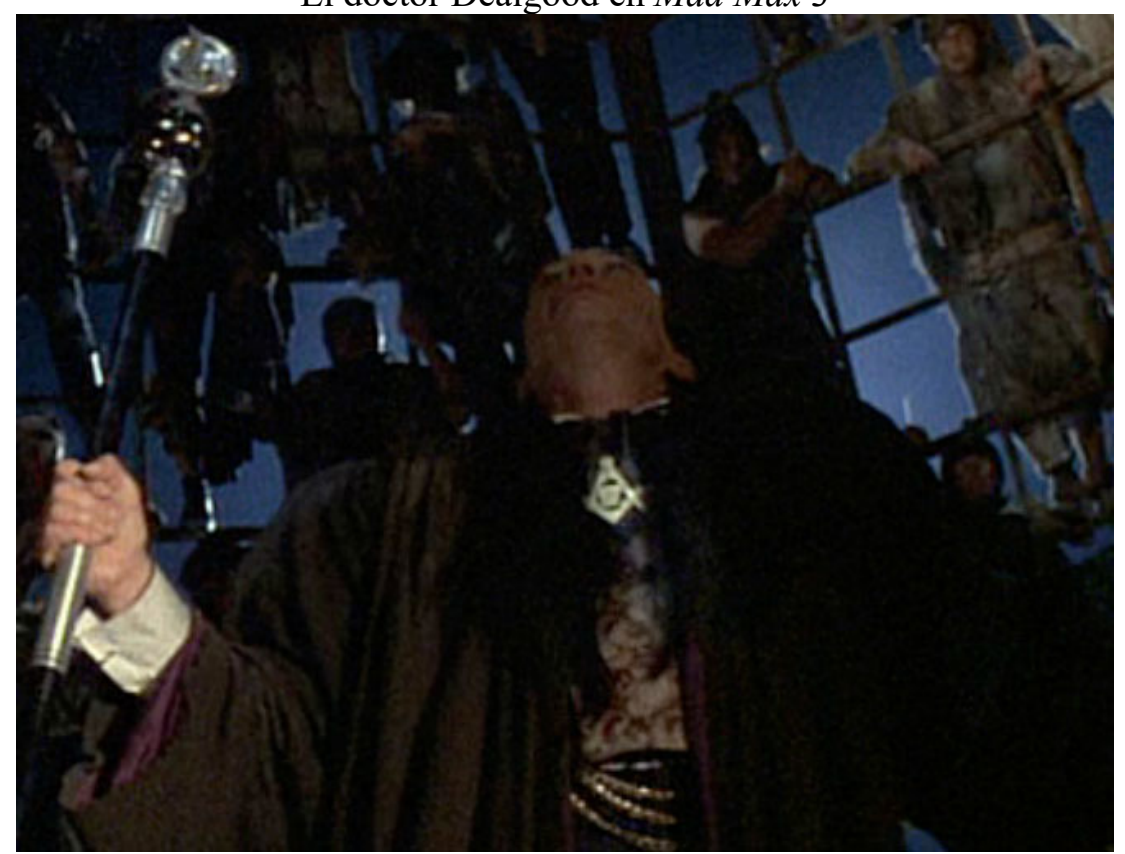

Fuente: https://i.pinimg.com/originals/e3/9a/f2/e39af2844270e8fc4d4d864bbf2e178e.jpg

En Flash Gordon (1980) -película que me encantó en mi infancia pero que no he vuelto a ver desde entonces- el enigmático general Klytus, mano derecha del malvado emperador Ming, usa como distintivo un emblema bordado en oro en el pecho que, sin lugar a dudas, está inspirado en la escuadra y compás masónicos. Cabe destacar que el general Klytus no forma parte del reparto original de Flash Gordon escrito por Alex Raymond, sino que fue un personaje inventado para esta versión cinematográfica por parte del guionista Lorenzo Semple. La única información disponible sobre el traje de Klytus es que fue diseñado por un equipo de vestuaristas que, en algún momento, trabajó con Fellini. Por tanto, no queda claro si la idea de bordarle una insignia inspirada por la escuadra y el compás fue del diseñador de vestuario, del guionista o del director. 


\section{Imagen 11}

El General Klytus, con su llamativa insignia dorada en el pecho

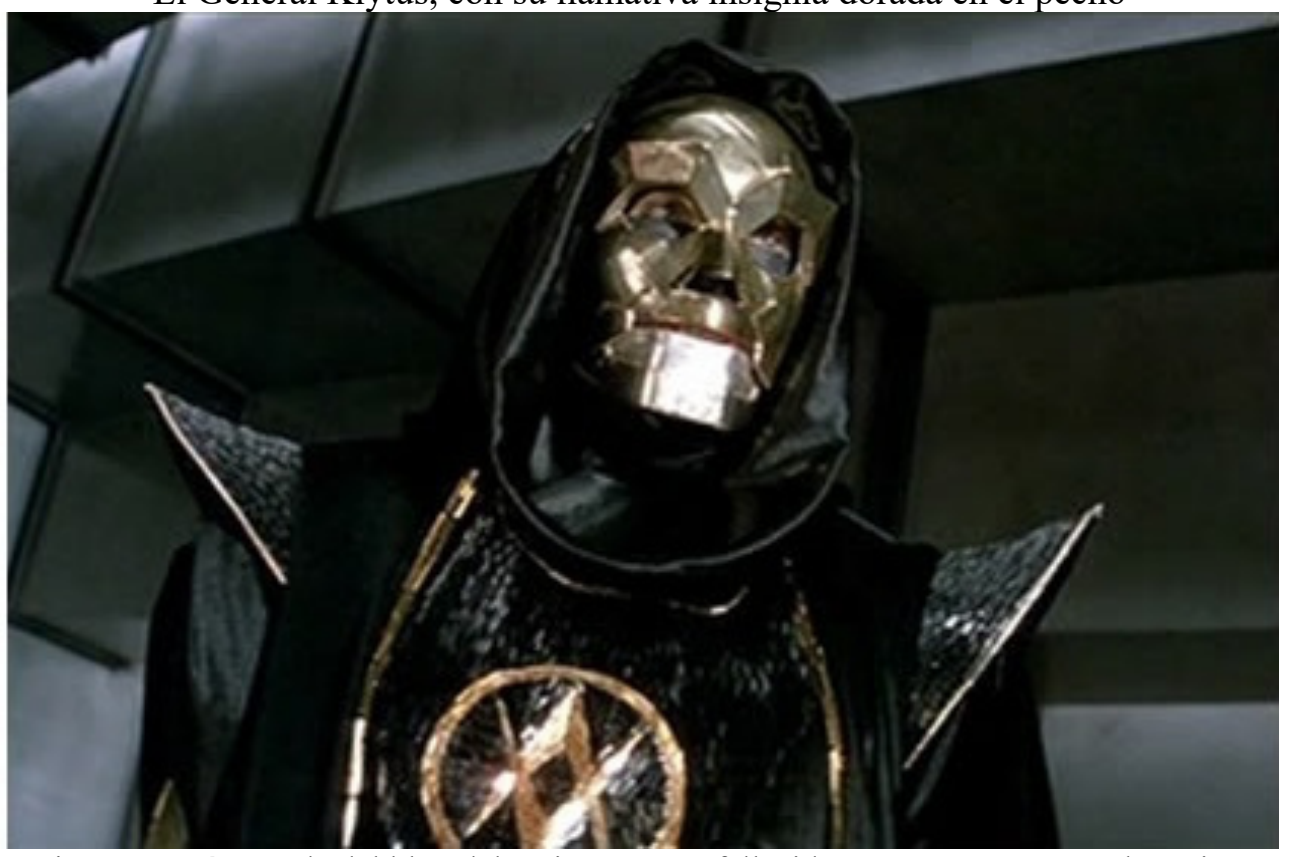

Fuente: Esta imagen está tomada del blog del recientemente fallecido actor Peter Wyngarde, quien personificó a Klytus en Flash Gordon, https://peterwyngarde.wordpress.com/2017/12/11/general-klytus-from-behind-themask/

\section{Imagen 12}

La figura de acción también incluye el símbolo. Es de extrañar que nadie afirmó en su momento que se trataba de una campaña para llevar a los niños hacia la masonería

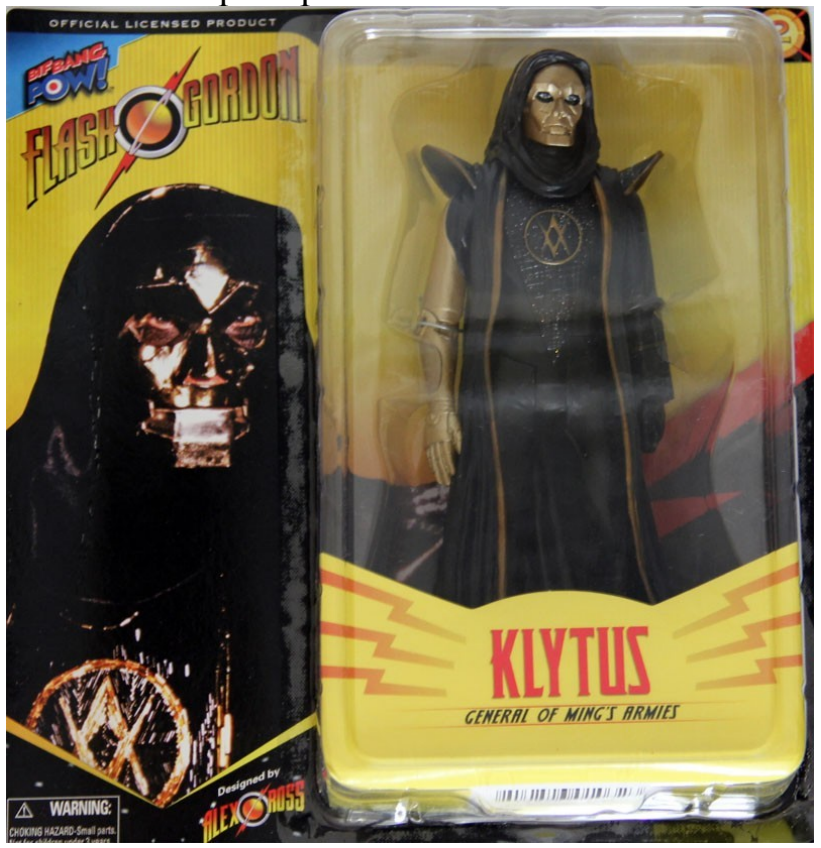

Fuente: eBay. 
Una película que resultó un desastre financiero y que, además, no tuvo una buena recepción ni entre el público ni por parte de la crítica - pero que yo, debo confesar, disfruté muchísimo-, fue The League of Extraordinary Gentlemen (2003). Basada en la serie de cómics escritos por Alan Moore -ojo con este nombre-, la trama gira en torno a las aventuras de un equipo formado por personajes de la literatura -el Capitán Nemo, Allan Quatermain, Mina Harker, el Hombre Invisible, Dorian Gray, el Doctor Jekyll y Tom Sawyer- que tiene como objetivo detener a Fantom, el villano que pretende iniciar una guerra entre Gran Bretaña y el Imperio Alemán para vender armas a ambos bandos. El equipo está formado por el misterioso personaje llamado simplemente $\mathrm{M}$, que resulta ser Moriarty -el archienemigo de Sherlock Holmes-. Pero, al final, se descubre que M/Moriarty y Fantom son el mismo. En tres escenas se dan las pistas para hacer la conexión entre M y Fantom. En primer lugar, cuando se reúnen por primera vez los miembros de la liga con $\mathrm{M}$, la puerta de acceso a la biblioteca de éste se encuentra adornada con símbolos de la escuadra y el compás. En otras dos tomas aparece Fantom, pero lo único que vemos de él es su mano enguantada y el enorme anillo con la escuadra y el compás que lleva en un dedo.

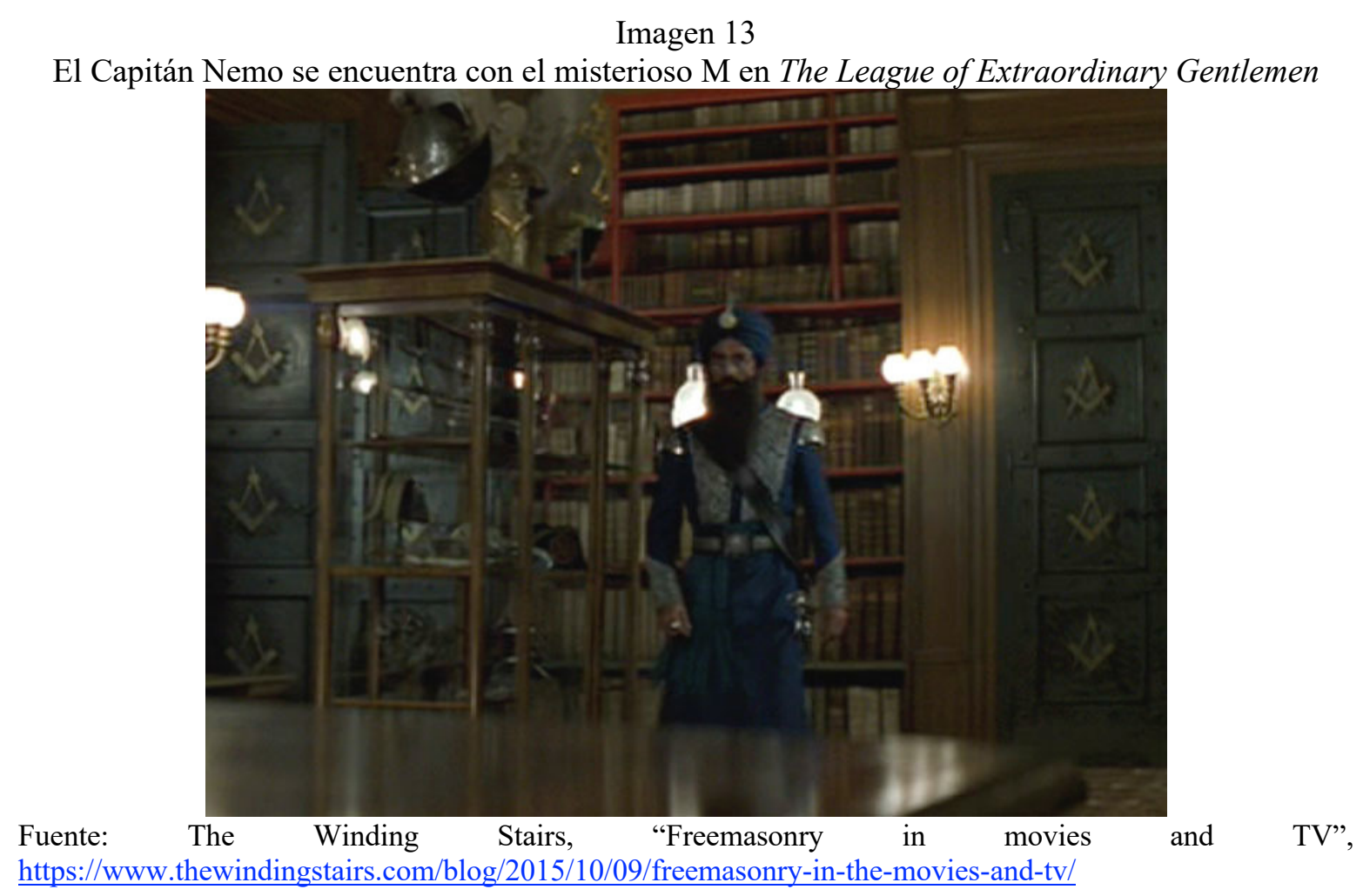




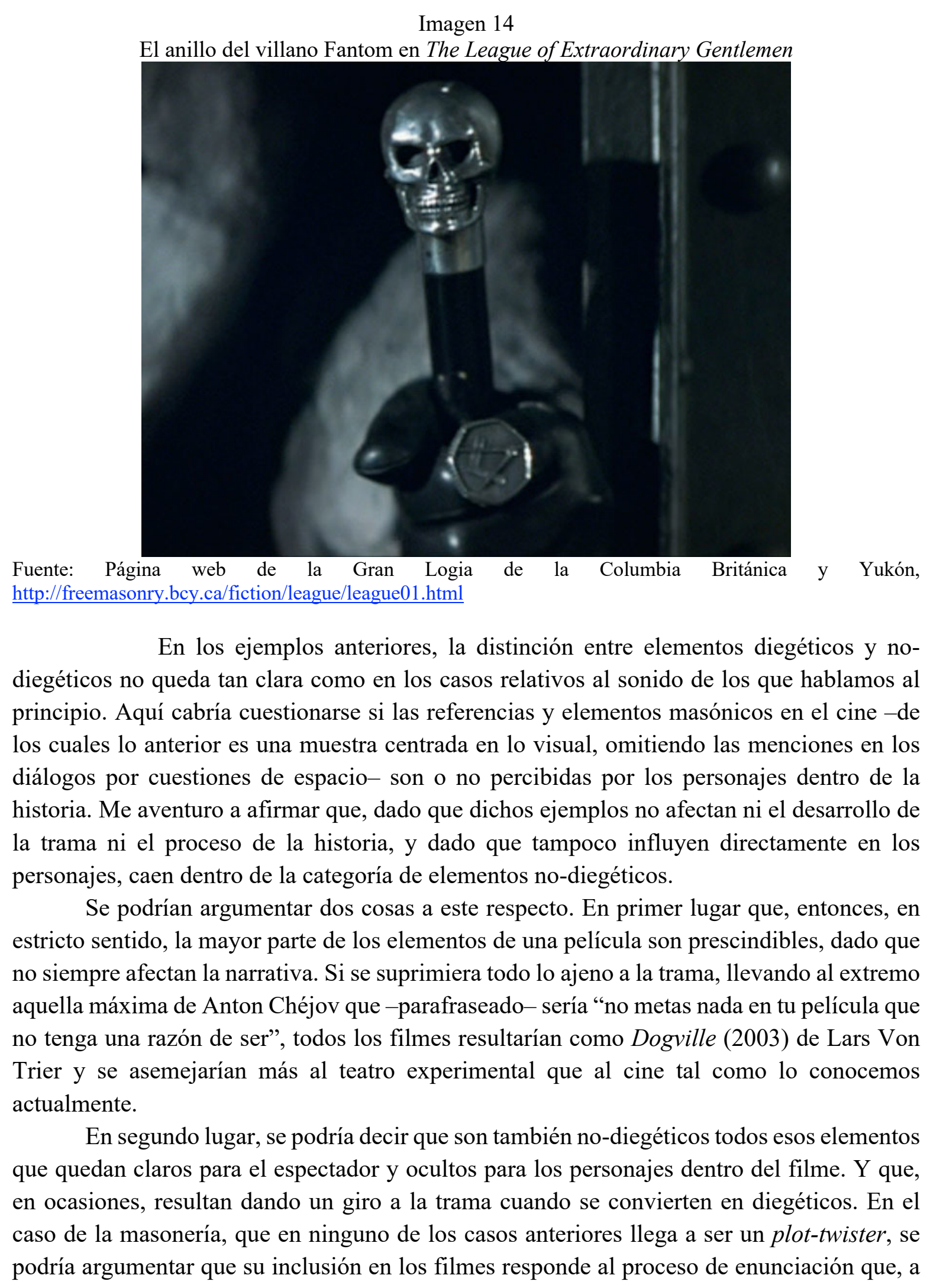


decir de algunos teóricos y críticos de los años 60,70 y $80^{4}$ del siglo pasado, estructura la relación del espectador con el filme y que -por ende- lo enunciado es producto de la enunciación y de su lugar ya que, al igual que el lenguaje, es una construcción social.

Desde este punto de vista de lectura «entre líneas» de una película -que contiene elementos de Lacan y de Derrida-, el espectador debe «desenmascarar» los elementos que parecen sencillos, naturales y realistas para darse cuenta que, en realidad, son complejos discursos determinados culturalmente. En épocas más recientes, algunos críticos han llevado estas ideas a otro nivel y proponen un análisis de las narrativas desde el punto de vista de las estructuras míticas y simbólicas que refuerzan o atacan. Así, cualquier elemento masónico en una película debería tener un trasfondo determinado por la estructura cultural del director, productor, guionista o cualquier combinación de ellos que haya decidido mostrar a la masonería bajo una luz determinada. Eso nos llevaría a concluir que los directores, guionistas y/o productores de Prisoners, We Own the Nighty Lonely Hearts tienen una cierta afinidad con la masonería y que, por el contrario, lo que tomaron las decisiones en Filth, Lone Star o The League of Extraordinary Gentlemen no ven a la masonería con buenos ojos. Es momento de hablar de tres largometrajes, uno hollywoodense, uno independiente y uno a medio camino, cuyo tratamiento de la masonería refuerza y ataca las estructuras míticas y simbólicas que se han construido en torno a dicha organización.

\section{Episodio 2: los «buenos», los «malos» y los «estéticos»}

A finales de 2013, el productor, director, actor y masón grado 32 Joseph James estrenó su tercer largometraje, aptamente titulado The Freemason. Al igual que sus dos producciones anteriores, The Masonic Map (2011) y Templar Nation (2012), tuvo un estreno muy limitado a pesar de contar como protagonista y productor ejecutivo a Sean Astin, mejor conocido por su interpretación de Samwise Gamgee en la exitosa versión cinematográfica The Lord of the Rings y por su papel de Mikey en The Goonies. The Freemason continúa sobre la misma línea de The Masonic Map. A saber, los masones son garantes y guardianes de un secreto ancestral que no debe caer en malas manos y son capaces de sacrificar sus vidas con tal de protegerlo. Mientras que la premisa de The Masonic Map es mucho más ambiciosa y medianamente más original -en 1502 los masones llevaron el Arca de la Alianza a Utah, en Estados Unidos, para mantenerla a salvo, encargando su resguardo a una tribu de nativos americanos y dejando como única pista de su paradero un mapa que los masones han protegido durante generaciones-, el argumento de The Freemason otorga un papel más

\footnotetext{
${ }^{4}$ Sin lugar a duda, el referente para estas cuestiones de teoría cinematográfica es Christian Metz. Para una panorámica de la obra de Metz y su importancia en este campo, véase John Lechte, "Christian Metz" en Fifty Key Contemporary Thinkers (Londres: Routledge, 1995), 77-81. Un resumen de los acercamientos teóricos a este tema se encuentra en http:/www.filmreference.com/encyclopedia/Independent-Film-RoadMovies/Narrative-NARRATIVE-THEORY.html
} 
protagónico a la masonería y a sus miembros, explotando esas estructuras míticas y simbólicas que se han creado alrededor de la organización y de sus componentes.

En cualquier caso, los personajes de esta producción son completamente arquetípicos, tan definidos que resultan aburridamente predecibles, insertos en una historia que tampoco ofrece el más mínimo atisbo de originalidad y que, en su estructura básica, se asemeja mucho a The Da Vinci Code. Habla del asesinato de un banquero, masón y acaudalado, que se produce dentro de una logia masónica -en Utah-. Rana, su única hija y aparente heredera universal, caracterizada a medio camino entre femme fatale y damisela en apuros, contrata a Cyrus Rothwell, un escritor/periodista independiente, escéptico y cínico, para que investigue el homicidio de su padre, dado que ella no confía en la policía. Sin embargo, a Leon Weed, el detective a cargo del caso, parece no importarle mucho la intromisión. E, incluso, se muestra servicial. Desde un principio, se nos muestran las dos actitudes más comunes hacia la masonería. Por un lado, para Weed los ritos masónicos son patrañas que no le provocan ningún interés. Pero, al mismo tiempo, Cyrus Rothwell desconfía del gran maestro y sospecha que los masones han conspirado contra su hermano banquero puesto que, al parecer, este en el testamento legó parte de su fortuna a la organización. Cyrus comienza a indagar más sobre ellos, descubriendo que su abuelo había sido masón y que, antes de morir, le había dejado - oculta en un libro antiguo- la misma nota que el banquero había transmitido a su hija dentro de un libro similar. Así, Rana y Cyrus descubren que el asesino persigue un secreto que los masones han guardado desde hace siglos, pero Rana está imposibilitada -por su condición de mujer- a acceder a él. Cyrus, quien en este momento ya está involucrado sentimentalmente con Rana y ya ha obtenido mucha información sobre la masonería de manos del gran maestro de la logia -más en estilo infomercial que hablando-, recibe un ultimátum. Le dicen que o se inicia en la masonería o jamás sabrá cuál es la información que están protegiendo. 


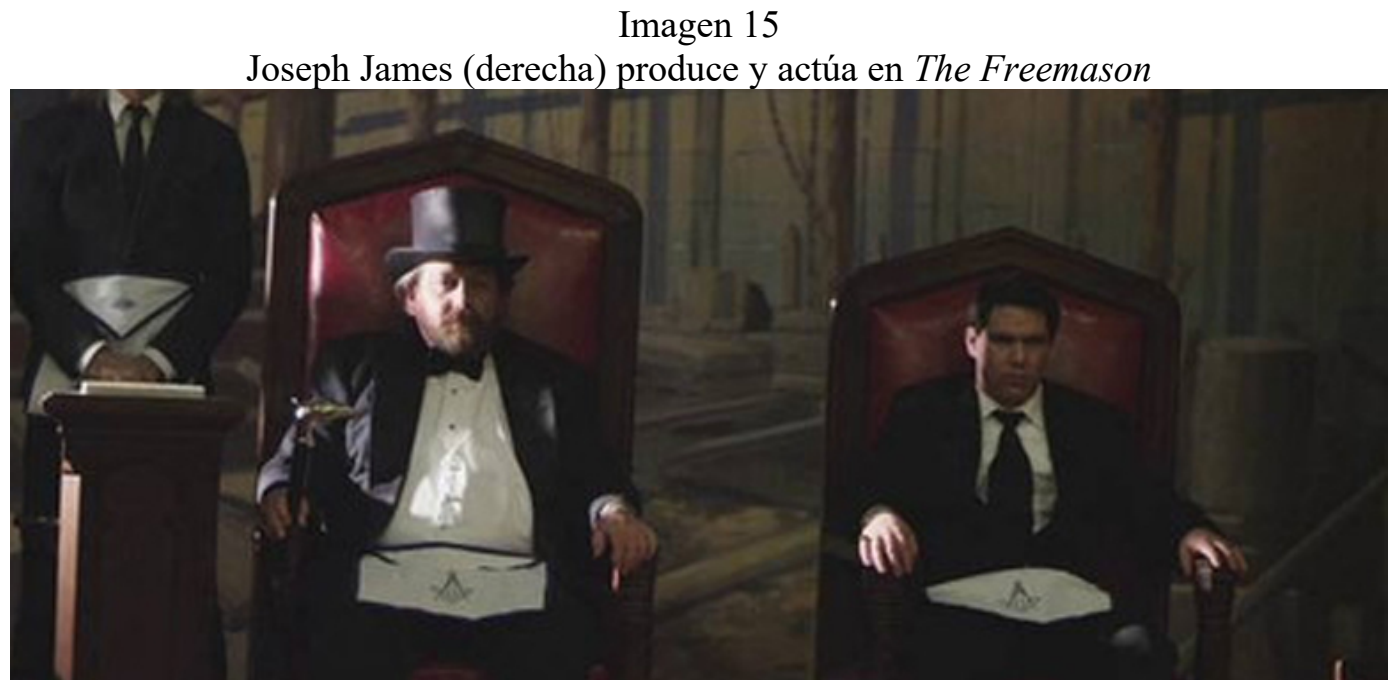

Fuente: Art Crime Illustrated, "The Freemason", http://www.artcrimeillustrated.com/2016/02/the-freemason2013-sean-astin-masonic.html

Cyrus, que al principio era escéptico y cínico, ahora es un ferviente convencido de la masonería. En consecuencia, acepta iniciarse. Le dan un par de horas y una decena de libros para aumentar su conocimiento sobre la organización antes de su entrada en la misma. En una secuencia sentimentaloide y cursi, los masones no votan unánimemente para aceptar la candidatura de Cyrus. Éste les dirige entonces un discurso, donde señala que ha cambiado de parecer respecto a la organización y que quiere ser un mejor hombre, como lo era su abuelo. Y que - además- se ha dado cuenta de que la ciencia no tiene respuestas para todo. Entonces, los masones quedan convencidos y aceptan a Cyrus Rothwell entre sus filas. Ya iniciado, se entera que el secreto custodiado por los masones y que busca el asesino es -nada más y nada menos- que la fórmula para convertir cualquier metal en oro... El espectador pensaría que en este punto se revelaría que dicha fórmula es parte de las enseñanzas simbólicas de la masonería, que en realidad es una metáfora de la transformación del hombre común en un hombre mejorado y que, por tanto, el filme continuaría sobre su línea de mostrar a la organización fraternal de forma positiva y medianamente realista. Pero no. En esta particular logia de Utah hay una especie de sociedad secreta llamada Aureus Sanctum, cuyos miembros son los guardianes de los escritos de Isaac Newton donde se describe el proceso para fabricar oro. Y dicha fórmula estaba escondida en los libros que el abuelo de Cyrus y el padre de Rana heredaron.

El asesino, que resulta ser el detective Leon Weed, secuestra a Rana, a Cyrus y al gran maestro de la logia, al que tortura para que le revele cómo funciona la fórmula para fabricar oro. El gran maestro expone que el abuelo de Leon pertenecía a «otra» orden, cuyo fin era manchar la reputación de los masones y esparcir ideas equivocadas sobre la masonería, e intenta convencer al ambicioso detective de que el verdadero secreto reside en el corazón de todo buen masón... Y justo es en este momento cuando su «contrincante» le dispara. Con su 
último aliento, el gran maestro le pide a Cyrus que no olvide su juramento. Leon amenaza con matar a Rana y Cyrus se ve obligado a decirle que lo que le hace falta a su fórmula es ácido bórico. Leon libera a Cyrus para que haga la mezcla química él mismo. La secuencia da a entender que al principio la fórmula funciona, pero no es estable y que el oro desaparece frente a los ojos del perplejo homicida. En la desesperación de ver su ambición frustrada, Leon depone su arma y es entregado a la policía. Cyrus entrega los manuscritos de Newton a la logia, promete seguir activamente en la masonería y se convierte, además, en miembro de Aureus Sanctum. Escribe un largo artículo sobre toda esta aventura, en el cual supuestamente están interesados los medios impresos más importantes de Estado Unidos. Pero, al final, es fiel a su juramento masónico, borra el artículo y vive feliz para siempre con Rana.

\section{Imagen 16}

La escena de la iniciación del personaje Cyrus Rothwell en The Freemason

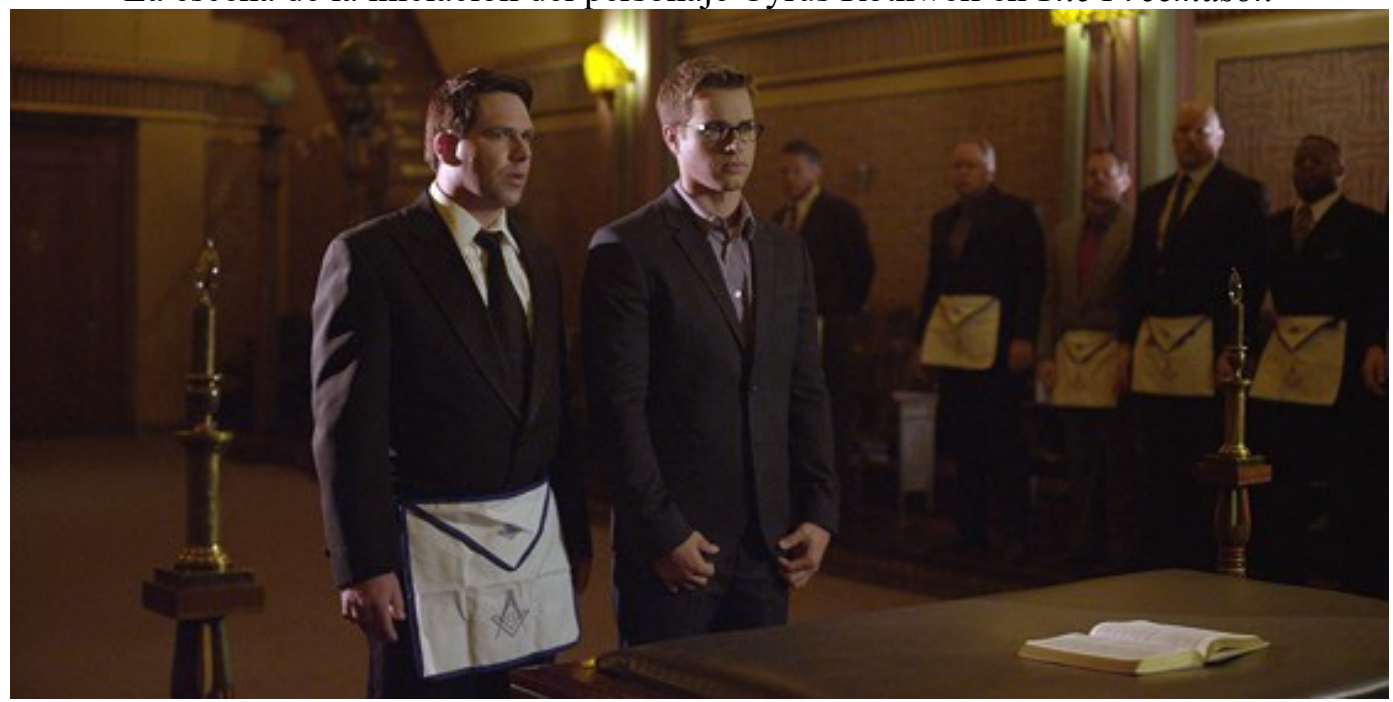

Fuente: Freemason Information, "Joseph James: teller of Masonic murders and mysteries", http://freemasoninformation.com/2014/07/joseph-james-teller-of-masonic-murders-mysteries-on-

freemasonry-and-the-cinema/

En su afán de ser, al mismo tiempo, defensa y promoción de la masonería y una película de suspense que explota los clichés más arraigados sobre dicha organización, The Freemason perdió la oportunidad de ser una película original, tanto en la trama como en la ejecución. Claro está que la filiación masónica del productor/actor Joseph James comprometió el tratamiento de su hermandad, por lo que este filme es un buen ejemplo de un intento narrativo aparentemente realista que termina siendo determinado por el lugar de su enunciación.

Un largometraje que no tiene ninguna pretensión de realismo, pero que intentó explotar el lado más sensacionalista de un acontecimiento verídico, es From Hell (2001), dirigida por los hermanos Allen y Albert Hughes y protagonizada por Johnny Depp, Heather 
Graham, Sherlock Holmes y Robbie Coltrane. La historia de esta película se nutre de varias fuentes: está basada muy vagamente en la novela gráfica del mismo nombre, escrita por Alan Moore -efectivamente, el mismo autor de The League of Extraordinary Gentlemen- y publicada entre 1989 y 1998, que a su vez parece haberse inspirado en el filme Murder by Decree (1979) y en el libro Jack the Ripper: the Final Solution (1976) escrito por Stephen Knight. Este autor fue también responsable de The Brotherhood (1984), otra obra literaria antimasónica, donde argumentó que los masones estaban detrás de los asesinatos de Whitechapel como parte de una conspiración para evitar un escándalo que pondría en entredicho la continuidad de la familia real británica ${ }^{5}$.

Imagen 17

Benjamin Kidney, cabeza de la sección especial de la policía londinense, amenaza al cochero

Netley para que colabore en los asesinatos en From Hell

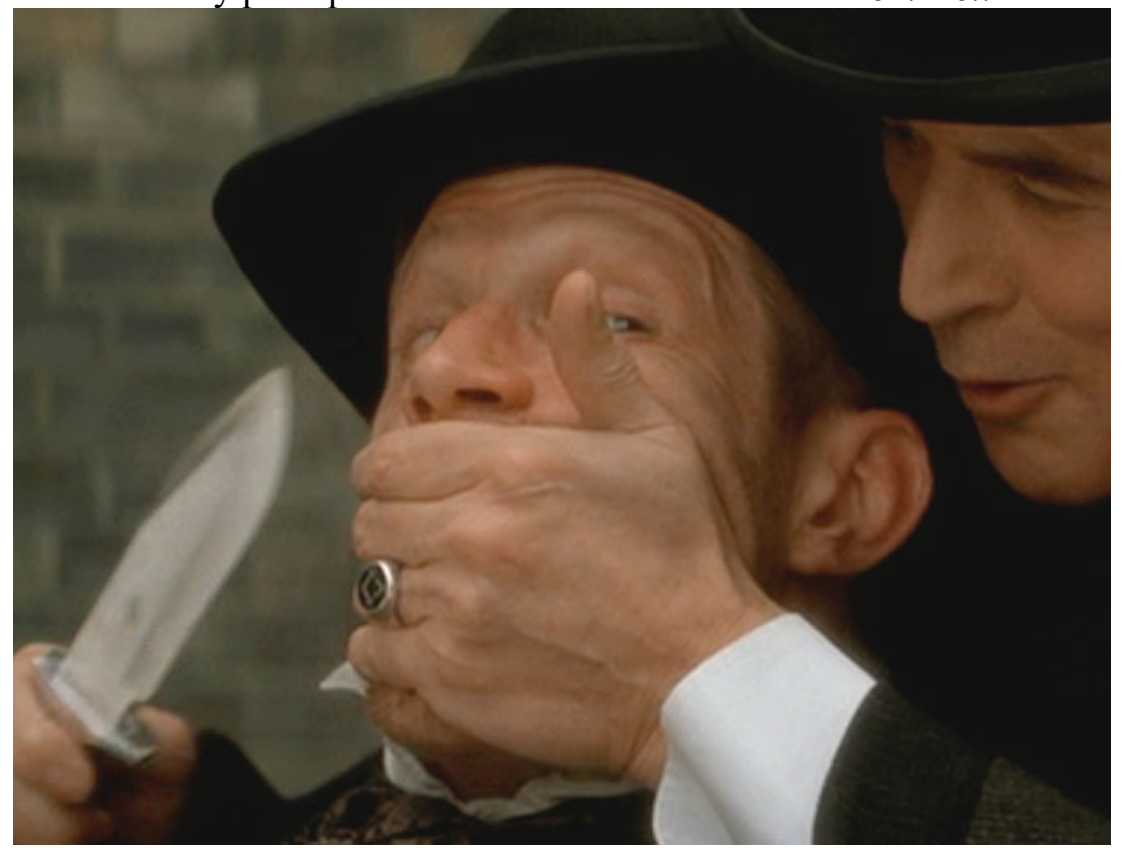

Fuente: "Masonry in movies", http://www.hs115.org/movies.html

Si bien la película de los hermanos Hughes y la novela gráfica de Moore llevan el mismo título, las diferencias en el tratamiento narrativo del tema son profundas. De hecho, el filme por momentos se acerca más al texto de Knight que a la obra de Moore, de donde toma su título. Mientras que la novela gráfica pone el acento en el porqué de los asesinatos, la película se centra en el quién. Antes de que hayan transcurrido 15 minutos del filme, ya

\footnotetext{
${ }^{5}$ Un largo y algo denso estudio sobre las adaptaciones denominadas "transmediáticas" de novelas a cómics/novelas gráficas - pero que por desgracia carece de una referencia a las adaptaciones cinematográficasse puede encontrar en Chiao-I Tseng y John A. Bateman "Cohesion in Comics and Graphic Novels: an empirical comparative approach to transmedia adaptation in 'City of Glass', Adaptation 11, no. 2 (agosto 2018): 122-143, https://doi.org/10.1093/adaptation/apx027
} 
hemos visto a Benjamin Kidney - jefe del cuerpo especial de la policía de Londres y masónamenazar a Nestley -el cochero del príncipe Albert-, entrar por la fuerza a la habitación donde se encontraban en secreto el heredero al trono y Ann Crook -su esposa, ilegítima por ser católica y plebeya-, secuestrarla para interrogarla sobre quiénes están al tanto de su relación con el noble y del fruto de ésta -Ann ha dado a luz a una niña, Alice, que sería la siguiente en la línea de sucesión al trono británico-, y, así, desencadenar los asesinatos en contra de las prostitutas de Whitechapel, amigas y confidentes de Ann, a cuyo autor material conocemos hacia el final de la obra audiovisual.

En el texto, en cambio, se crea un contexto más amplio y la identidad del asesino queda clara desde el quinto capítulo del primer libro. Sin embargo, lo que se nos va descubriendo este trabajo son los motivos que llevan a cometer los asesinatos y todo el trasfondo ritual y de lealtad que encierran. La versión cinematográfica representa los crímenes más como un fin en sí, como una solución práctica a un problema real -en ambas acepciones de la palabra-, en donde el aspecto ritual es un mero accesorio que termina sirviendo de pista para que el astuto Abberline dé con el asesino. El cómic nos muestra que la forma en que se llevan a cabo los homicidios tiene un profundo significado ritual y simbólico para el destripador, quien está menos preocupado por ocultar su identidad que por realizarlos según un plan esotérico perfectamente establecido.

\section{Imagen 18}

El actor Ian Holm interpreta a sir William Gull, el autor material de los asesinatos de las prostitutas de Whitechapel, en From Hell

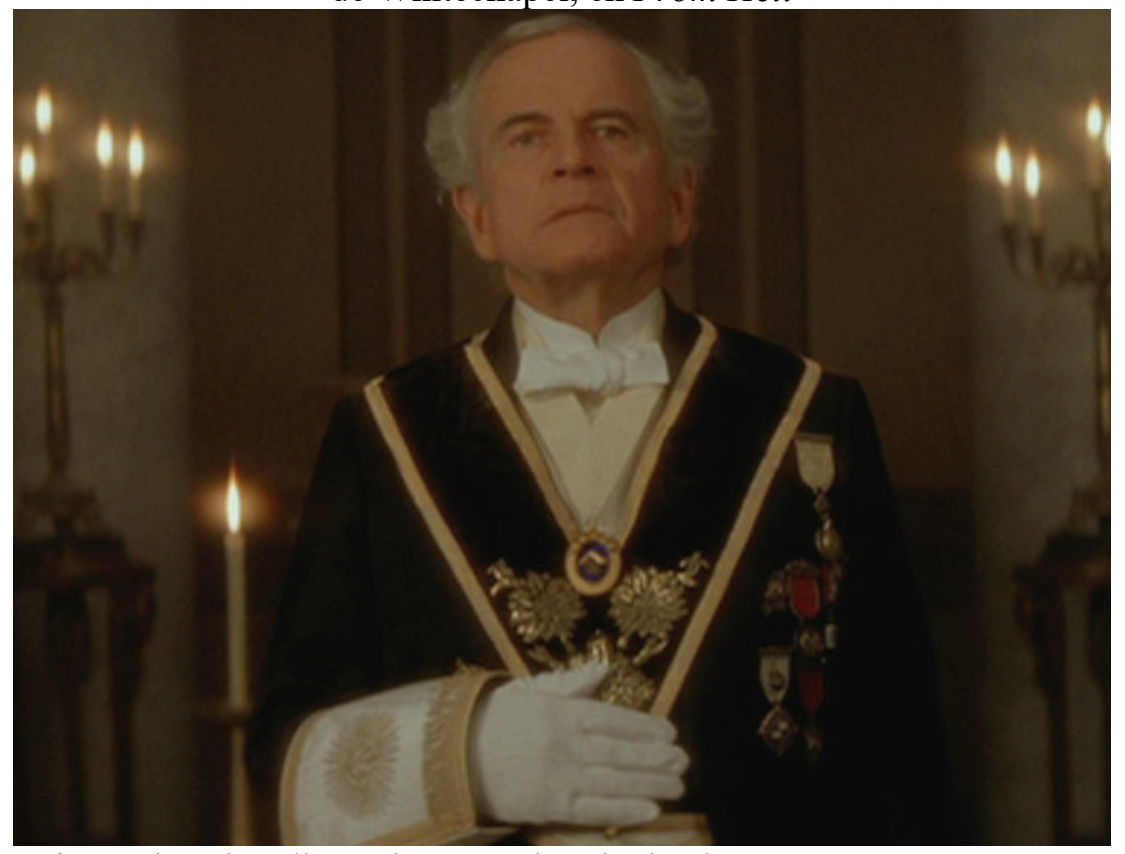

Fuente: "Masonry in movies", http://www.hs115.org/movies.html 
El largometraje presenta a los masones como los autores intelectuales de los asesinatos, perpetrados con el fin de encubrir al heredero al trono, que a su vez también es masón y nos lleva a inferir que la reina Victoria no estaba al tanto del plan de la hermandad. Pero en la obra de Moore la conspiración comienza precisamente con la monarca, quien se entera que su nieto tiene una hija ilegítima y católica. Ello gracias a que las amigas de Ann Crook, las prostitutas de Whitechapel, han caído en la cuenta de la verdadera identidad del padre de Alice y pretenden chantajearla. La reina pide a sir William Gull -su médico y hombre de confianza- que se encargue de eliminar las amenazas en contra de la estabilidad de la monarquía británica. Gull es masón y mueve sus influencias con sus hermanos para llevar a cabo su plan sin contratiempos. En el filme, sir Charles Warren, el jefe de la policía londinense y superior directo del inspector Abberline (Johnny Depp), encargado del caso, se encuentra iniciado y está al tanto de todo desde un principio, por lo que trata de desviar la atención de su subordinado sugiriéndole que investigue a los judíos o a un grupo teatral de nativos americanos que están de paso por Londres como posibles autores de las muertes. En la novela gráfica, Gull ya tiene el plan de asesinar a las prostitutas cercanas a Ann Crook y acude con Warren a explicarle todo. Warren se rehúsa a asistirlo, pero Gull juega la carta masónica: el deber del jefe policiaco es ayudar a su hermano a ayudar a otro hermano y guardar el secreto. Warren cede y asigna el patrullaje de Whitechapel a policías que también son masones y sabrán guardar silencio. Así, mientras que el filme presenta a la masonería como el cerebro del plan, el texto la pone como un mero instrumento.

Y ya que hablamos de diferencias, la película Murder by Decree, dirigida por Bob Clark -mejor recordado por la trilogía de Porky's- y protagonizada por Christopher Plummer, se basa en la premisa del libro de Knight, pero sustituye los nombres de los personajes con referentes en la realidad -el cirujano Gull, el chofer Nestley y el inspector Abberline- por personajes ficticios, quedando únicamente sir Charles Warren y el primer ministro lord Salisbury basados en los personajes reales -y además son quienes cargan con la autoría de la conspiración y su encubrimiento-. De hecho, en este largometraje los encargados de investigar los casos son nada más y nada menos que Sherlock Holmes (Christopher Plummer) y su inseparable Watson (James Mason). En esta versión los masones tampoco salen bien parados y, apegados a la idea de Knight, son los responsables únicos y directos de la conspiración para encubrir al asesino y evitar el escándalo en la familia real. 
Imagen 19

William Gull revela a la reina Victoria el verdadero motivo de los asesinatos rituales en la novela gráfica From Hell
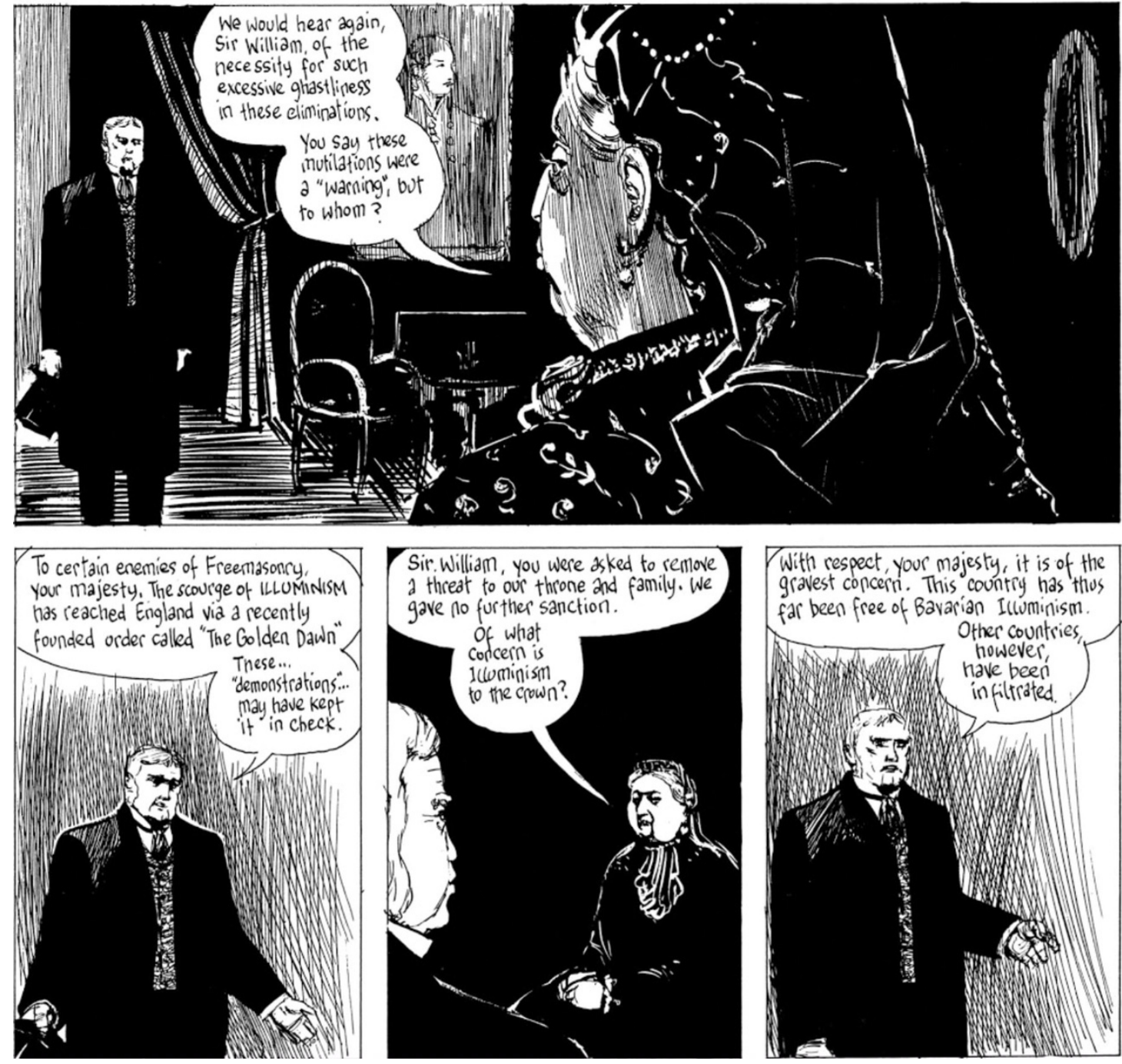

Fuente: https://readcomiconline.to/Comic/From-Hell-2009

En los tres casos anteriores, las versiones cinematográfica y novelada de From Hell y Murder by Decree, nuevamente el lugar de la enunciación determina al discurso narrativo. Sin embargo, ese lugar de enunciación no es el más aparente. De entrada, se podría pensar que los directores o los guionistas de ambas películas guardaban algún sentimiento antimasónico que intentaron expresar en sus respectivos trabajos cinematográficos. También se podría argumentar que Alan Moore, que es un declarado seguidor de Aleister Crowley, el esoterismo occidental y el pensamiento trans-racional, tiene algo en contra de la masonería. Pero recordemos que Murder by Decree precede a las primeras entregas del cómic From Hell por una década y a la versión cinematográfica por un poco más de dos, que tampoco es la primera película que enfrenta a Sherlock Holmes con Jack el Destripador-ese honor lo tiene 
A Study in Terror de 1965-. Pero sí es la primera obra de ficción llevada a la pantalla grande que involucra a los masones con los asesinatos de Whitechapel.

Por ende, el elemento en común de las tres entregas que presentan a Jack el Destripador como una conspiración masónica es The Final Solution, del periodista Stephen Knight. Hablar de esta obra escapa por completo los límites del presente trabajo y, dado el nivel de detalle, las conexiones del texto con otras investigaciones, el elemento ficticio y la polémica que generó - sin mencionar que el autor murió a los 33 años en 1985, lo que avivó las teorías de conspiración masónica ${ }^{6}$-, analizar los textos de Knight amerita un trabajo de investigación más serio y profundo.

Pero ya que menciono el elemento ficticio del trabajo de Knight, aprovecharé la ocasión para criticar a los críticos. El Final Solution de Knight está basado en el testimonio de un tal Joseph Borman, que sin ofrecer mayores pruebas afirmaba ser hijo de Alice $-\mathrm{y}$, en consecuencia, nieto de Ann Crook y del príncipe Alberto-. También aseguraba que su padre, el pintor Walter Sickert -que era amigo cercano de Alberto-, fue quien le contó toda la historia de la conspiración para ocultar la existencia de su madre. A pesar de que Borman no aportó pruebas de su aseveración -e, incluso, tiempo después se retractó y admitió que todo había sido un engaño-, Knight presentó su investigación como una historia verídica. Y, por ese lado, llegaron las críticas, dado que el argumento era endeble y no había forma de verificar que tuviera referente en la realidad.

Resulta curioso que las críticas a ambas versiones de From Hell, especialmente en los círculos masónicos, vienen en el mismo sentido, a pesar de que ninguna de ellas tiene pretensiones de veracidad ni afirman estar sostenidas sobre bases reales. Si, como han dicho los masones, William Gull no fue miembro de la masonería, si las ceremonias y rituales representados no son exactamente como los realizan en sus logias, o si algunos aspectos de la mitología masónica están claramente inventados, todo eso no debería ser la parte medular de la crítica, puesto que nos enfrentamos a obras de ficción, que en el más estricto sentido tienen licencia creativa para relatar su historia en la forma que mejor les convenga. Y queda claro que la crítica siempre tiene también un lugar de enunciación que la determina social, cultural e históricamente. El mejor ejemplo es, precisamente, la falta de apreciaciones más detalladas desde la masonería a la ya mencionada The Freemason, a pesar de las descaradas fabricaciones que incluye en su historia con el fin de adecuarla a su narrativa. El único argumento medianamente negativo hacia la película, esgrimido por una entidad masónica, considera que el uso de la organización para relatar la historia fue "gratuito", en el sentido de que se pudo haber usado cualquier otro telón de fondo para la acción, e ironiza el supuesto

\footnotetext{
${ }^{6}$ Como generalmente sucede en estos casos, la Internet es la mejor fuente para enterarse de esta clase de hipótesis. Recomiendo, por su inventiva y virulencia, las siguientes páginas: https://kpoulin1.wordpress.com/2007/06/25/stephen-knight-murdered-by-freemasons/; https://dreamweaver11 gold.wordpress.com/2012/01/23/confessions-from-an-ex-freemason-to-stephenknight/; https://www.henrymakow.com/uk-insider-exposed-masonic-control-.html
} 
éxito del filme mencionando que ya se prepara una secuela. Sin embargo, de las inconsistencias y licencias cinematográficas, ni una palabra ${ }^{7}$.

Por último, el hueso más difícil de roer. Difícil por la complejidad de su estructura narrativa, por la inaccesibilidad del material y por la cantidad de interpretaciones posibles que se pueden hacer de la obra, en su conjunto y en sus partes ${ }^{8}$. Me refiero al Cremaster Cycle, del artista estadounidense Matthew Barney. Este ciclo de cinco películas, tituladas en honor al músculo cremáster, que es el responsable del movimiento ascendente y descendente de los testículos, se produjo en desorden secuencial - la primera entrega fue la parte cuatro y la última, la tres- entre 1994 y 2002. Barney ha rehusado terminantemente a comercializar el ciclo, por lo que no está disponible en DVD ni en ningún otro formato de consumo masivo. Tampoco se puede consultar YouTube ni en ninguna otra plataforma digital. Y de hecho Barney y su equipo vigilan constantemente internet para evitar que alguien cuelgue copias ilegales en algún lugar. Tuve la fortuna de ver la tercera parte -que es la pertinente para este recuento de la masonería y el cine-en YouTube hace un par de años. Ahora ha desaparecido casi por completo de dicha plataforma, ya que quedan únicamente pequeños fragmentos aislados de pocos minutos de duración. Las últimas proyecciones públicas del ciclo completo se realizaron en el año 2006, así que las probabilidades de ver estos filmes son prácticamente nulas. Dicho lo anterior, lo que presentaré a continuación es mi interpretación personal de la colección -que nunca vi- a partir de reseñas, testimonios y críticas, así como de la tercera entrega -que sí pude disfrutar en sus tres horas de frenesí visual-.

Cremaster Cycle es una alegoría visual, prácticamente carente de diálogo, de las distintas etapas biológicas del ser humano, en específico del género masculino. En la parte primera se hace referencia al momento de la concepción y la subsecuente división celular en estado "puro", es decir, sin género. Y el ambiente es festivo y musical. La segunda parte se centra en la fase fetal, en el momento que inicia la diferenciación sexual del producto y el

\footnotetext{
${ }^{7}$ El texto completo -que en realidad son apenas un par de párrafos- se puede encontrar en la página de internet de la Gran Logia de la Columbia Británica y el Yukón, directamente en este enlace: http://freemasonry.bcy.ca/fiction/images/the freemason.html

${ }^{8}$ Acerca del ciclo de cinco películas de Matthew Barney es posible encontrar todo tipo de opiniones e interpretaciones. Desde reseñas en periódicos y revistas no especializadas (como esta, aparecida en The Guardian: https://www.theguardian.com/artanddesign/2015/jul/14/matthew-barney-cremaster-cycle-art-film) hasta una página web manejada por admiradores de la pentalogía y su autor (http://www.cremasterfanatic.com). Entre los análisis académicos más interesantes, tenemos los siguientes: David Bjelajac, American Art: a cultural history (Nueva Jersey: Prentice Hall, 2005), 469-472; Arthur C. Danto, "The Anatomy Lesson. Matthew Barney's Cremaster cycle", The Nation, 17 de abril de 2003, https://www.thenation.com/article/anatomylesson/; Hélene Frichot, "Matthew Barney's Cremaster Cycle revisited", Angelaki 20, no.1 (2015): 55-67, https://doi.org/10.1080/0969725X.2015.1017376; Lynn Brunet, "Homage to Freemasonry or indictment? The Cremaster Cycle", PAJ: A Journal of Performance and Arts 31, no. 1 (enero 2009): 98-112, https://www.mitpressjournals.org/doi/abs/10.1162/pajj.2009.31.1.98; Alexandra Keller y Frazer Ward, "Matthew Barney and the Paradox of the Neo-Avant-Garde Blockbuster", Cinema Journal 45, no. 2 (invierno 2006): 3-16; Andy Ditzler, "The epic ambiguity and cinematic genius of Matthew Barney's Cremaster Cycle", Artsatl, 19 de septiembre de 2010, https://artsatl.com/review-andy-ditzler-on-the-epic-ambiguity-andcinematic-genius-of-matthew-barneys-cremaster-cycle/
} 
drama de la resistencia al cambio y a ser manejado por las fuerzas del destino. La cuarta entrega-que en realidad fue la primera en producirse- hace hincapié en las transformaciones de la madurez. Y la quinta gira en torno a la trascendencia y la muerte.

Imagen 20

El aprendiz durante la secuencia llamada "The Order" en Cremaster 3

Fuente: https://scpt209.files.wordpress.com/2012/09/3.jpg

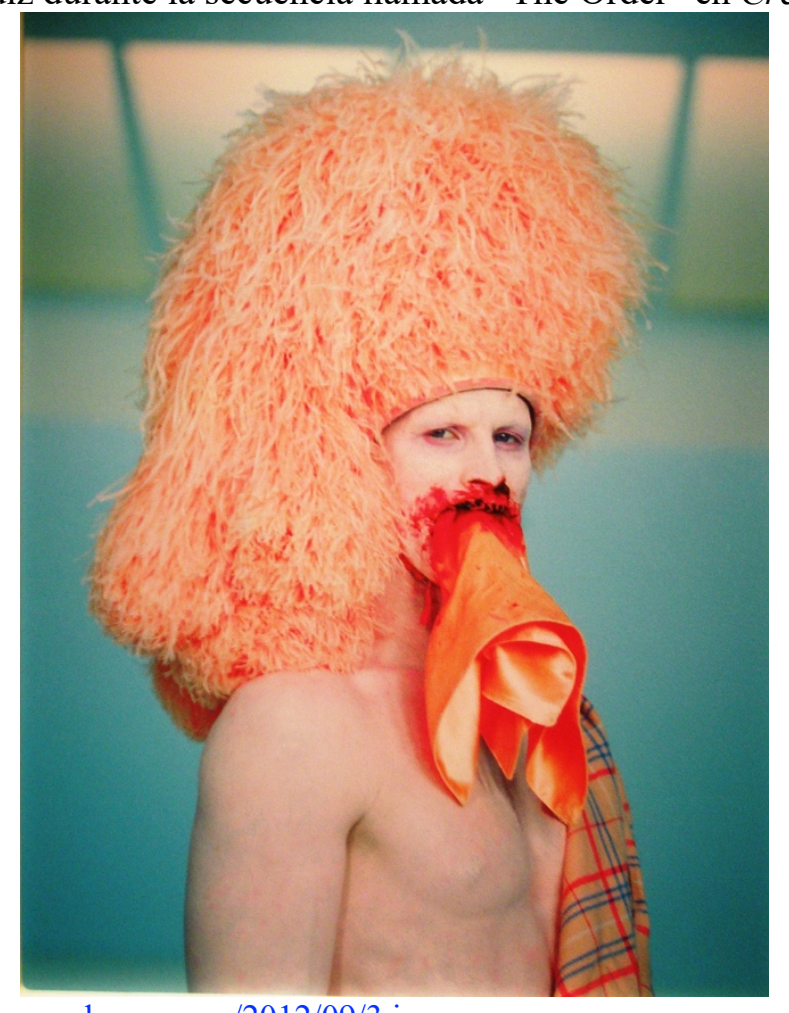

Cremaster 3 es una alegoría de las últimas etapas de la gestación, el nacimiento y la infancia, representados a través de una serie de secuencias que evocan ritos de paso y de iniciación a la «masculinidad» desde el punto de vista social y personal. Así, tanto los personajes de Hiram Abiff como del aprendiz están inmersos en la construcción del edificio Chrysler en Nueva York - un símbolo fálico- y están en franca competencia por finalizar la edificación. Siguiendo la tradición masónica, y envuelto en un lenguaje visual que hace referencia a la hermandad en cuestión, Hiram (la sociedad) es el depositario del conocimiento de los misterios del universo y el aprendiz (el hombre) debe sortear los ritos de iniciación para pasar de esa etapa temprana al grado de maestro, es decir, a dominar lo que significa ser un hombre en el mundo. Pero en todo este proceso, el drama de la resistencia a la incontrolable fuerza del destino se sigue haciendo presente, simbolizado por el cadáver de una mujer que es depositado dentro de un automóvil que después tomará parte en una carrera de demolición. El aprendiz coloca cemento en los coches que participarán en la carrera para incrementar su poder destructivo. Y se da cuenta que con dicho cemento puede moldear la 
piedra sillar, el símbolo masónico de la rectitud moral y del equilibrio, contrario a la piedra en bruto del hombre no iniciado. Así, el aprendiz moldea la piedra y hace trampa en su iniciación, ya que se salta todos los pasos y escapa del edificio, es perseguido por dos hombres -masones- que lo golpean y lo dejan sin dientes. Regresa al edificio Chrysler y acude con un dentista. El aprendiz se quita la ropa y debajo trae puesto todavía un mandil, fabricado como de su propia piel pues parece que cuelga de su vientre. Hiram se encuentra con el aprendiz en el consultorio dental y le hace tragar piezas de coche hasta que sus órganos internos le salen por el recto.

Imagen 21

El aprendiz en el dentista, rodeado por Hiram Abiff y sus secuaces

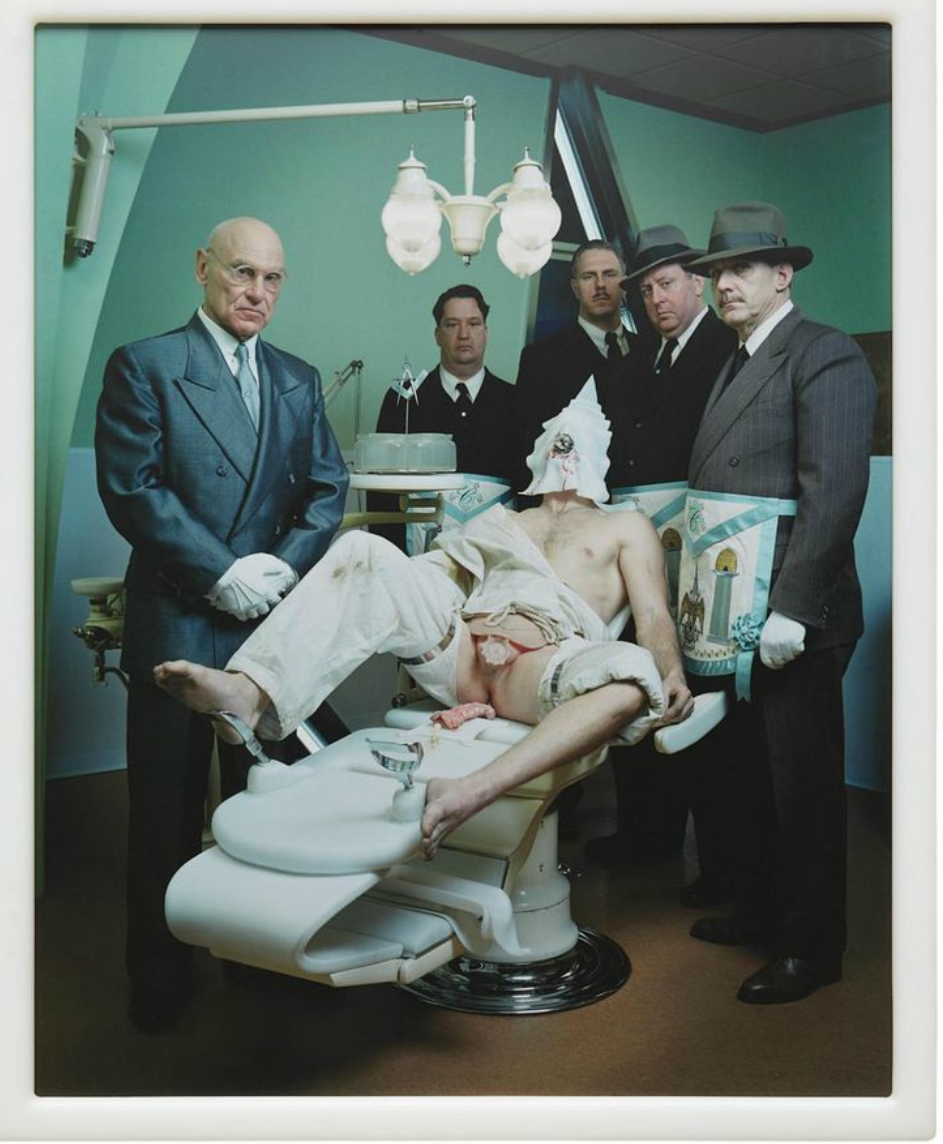

Fuente: https://i.pinimg.com/736x/73/ea/2f/73ea2ff746cfbd0b2a140415ad591215.jpg

El aprendiz escapa de nuevo y llega a un lugar -que aparentemente es el museo Guggenheim-donde participa de una especie de juego llamado «The Order», donde él es el único concursante y en el que se le obliga a sortear obstáculos. Entre ellos, enfrentarse a la atleta Aimee Mullins -vestida de novia posmoderna y masónica que se transforma en una mujer-leopardo- y al escultor Richard Serra, que está arrojando manteca de cerdo derretida 
al piso. Esta parte es, posiblemente, la más estridente de la película, tanto visual como auditivamente, ya que la música muta -rápidamente y al azar-entre el big band, la electrónica y el rock punk. Para muestra, un botón: en la segunda etapa de «The Order», mientras el aprendiz realiza sus pruebas -una de las cuales consiste en encontrar un mallete, una escuadra, un compás y una plomada ocultas en una especie de escultura en forma de cruz latina incrustada en el suelo-, dos bandas de rock punk tocan al tiempo que un grupo de personas hacen slam en círculos alrededor del aprendiz, que va ataviado con un kilt hecho de tartán color rosa fluorescente, una enorme peluca/sombrero del mismo color y pedazo de tela que le sale de la boca desdentada y sangrante.

Imagen 22

Aimee Mullins (izquierda) y Matthew Barney en Cremaster 3

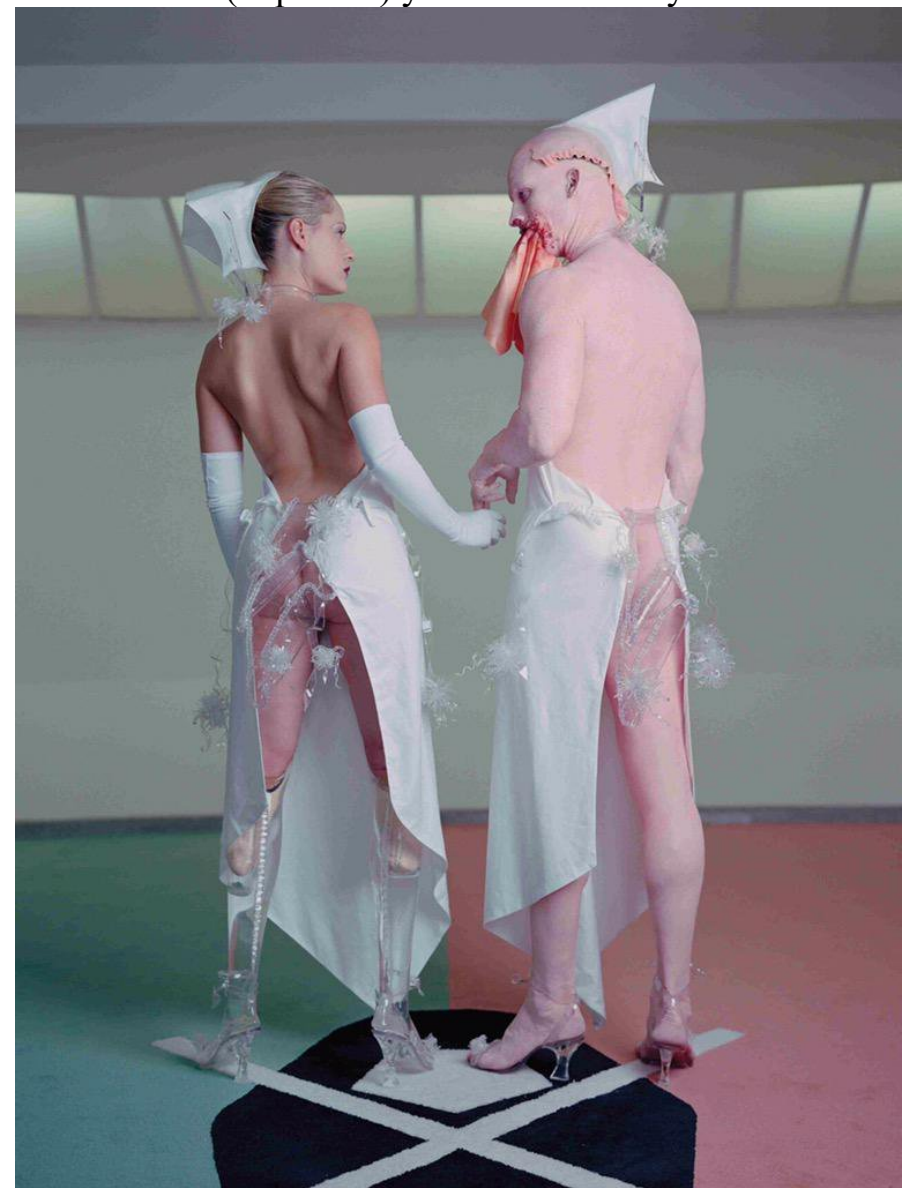

Fuente: http://pbs.twimg.com/media/CNdE_dNUAAAGgDG.jpg:large

Tras sortear el juego, el aprendiz se reencuentra con Hiram Abiff, que ha continuado con la construcción del edificio Chrysler y ha levantado las columnas Jachin y Boaz. Ambos suben a la punta del inmueble, el aprendiz mata a Hiram, quien se transmuta en su propia creación, y entonces el rascacielos mata al aprendiz. 
En esta tercera parte -que en realidad fue la última en producirse y exhibirse- del Cremaster Cycle, la masonería queda despojada de su representación maniquea y maniqueizante, puesto que ni Hiram Abiffni el aprendiz pueden catalogarse como «buenos» o «malos» en el estricto sentido de la estructuras míticas y simbólicas que -como vimos en ejemplos anteriores- propone y refuerza la cinematografía hollywoodense. Pero se mantiene y se refuerza el papel simbólico de esta organización y su calidad iniciático-ritualista, aspecto que encaja a la perfección con la propuesta narrativa del filme, al menos desde mi personal interpretación. Así, Barney se sirve de la masonería y sus rituales como símbolos de los ritos de paso e iniciación, sociales y personales, a los que se enfrenta cada persona del género masculino en su paso por el mundo, narrados dentro de una estructura onírico-surrealista que remite más a los elementos del psicoanálisis que al uso de substancias psicotrópicas. Todo esto presentado desde una estética extraña y estridente, que bordea siempre lo grotesco y lo extraño, pero sin llegar a ser perturbadora.

\section{Episodio 3: Wall Street}

Como hemos podido ver en este breve pero frenético periplo a través de algunos ejemplos de la presencia de la masonería en el cine, es difícil catalogar su inclusión en la historia y la trama de los largometrajes donde se ha hecho alguna referencia a esta organización. Evidentemente no podríamos hablar de un género. Ni siquiera considero que cabría dentro del subgénero de películas que se centran en o que -simplemente- mencionan sociedades secretas, cultos o sectas esotérico-ocultistas del estilo Eyes Wide Shut, Anatomie, Die Welle o Angels and Demons. Tampoco se les puede asociar con la miríada de documentales sobre masonería de alto presupuesto que aparecen constantemente en la televisión a través de Discovery Channel, National Geographic o History, ni con sus contrapartes independientes y caseras que pueblan YouTube -ambas ramas piden a voces un estudio serio y académico-. Tampoco se les podría clasificar por época o por país, aunque la gran mayoría de los largometrajes mencionados son estadounidenses. Y esto último puede darnos un indicio del enorme peso que tiene la pertenencia a un círculo social en ese país y su inclinación por categorizar y categorizarse dentro de grupos étnicos o raciales, religiosos, universitarios, deportivos, laborales y un largo etcétera.

Entonces, ¿cómo explicar la presencia de elementos masónicos en el cine? A riesgo de sonar demasiado simplista y reduccionista -cínico dirían algunos-, aventuro la hipótesis de que puede responder a factores comerciales. La masonería vende, puesto que su carácter secreto -0 discreto si se prefiere- y el halo de misterio, corrupción, colusión y conspiración que se ha creado alrededor de ella en los últimos tres siglos, despierta curiosidad entre el público e -incluso- inquietud entre algunos, que -cayendo redondos en esta estrategia comercial- piensan que la masonería controla a Hollywood. Algo que haría patente a través 
de estas breves apariciones en la pantalla grande. Incluso el filme The Freemason, concebido y creado desde la masonería, no pudo evitar la tentación de incluir en su trama una sociedad secreta dentro de una sociedad secreta que protege un misterio, con el fin de hacer más atractivo el producto y vender más localidades o copias en DVD.

Ahora que las salas de cine se están quedando vacías y la tendencia gira hacia el streaming, tal vez se abran nuevas posibilidades para representar a la masonería en la pantalla, como la nueva comedia de la cadena AMC titulada Lodge 49 -estrenada en la segunda mitad de 2018-, que presenta una sociedad secreta evidentemente basada en la masonería, pero vista desde una perspectiva más relajada al estilo sit com. Claro está que persisten los clichés y los lugares comunes -incluso en el formato para streaming-. Basta ver la autocomplaciente y proselitista serie documental Inside the Freemasons (2017), que ahora está disponible en Netflix, la cual muestra a la masonería como una asociación de camaradería, amistad y filantropía donde abundan la comida, la bebida y las ceremonias, con grandes logias y grandes maestros, rodeado todo de grandes oropeles. Pero, sobre todas las cosas, los niveles de audiencia y los resultados positivos en la hoja de cálculo son los que cuentan, incluso por encima de la recepción crítica, la pertinencia o la innovación en el tratamiento de los temas. Así que, al menos en el futuro cercano, auguro que seguiremos viendo, en las pantallas de todos tamaños, las trilladas representaciones de la masonería que seguirán reforzando los mismos conceptos que hemos construido alrededor de dicha fraternidad desde siempre, de los cuales el cine refleja, apenas, una fracción mínima. 


\section{Imagen 23}

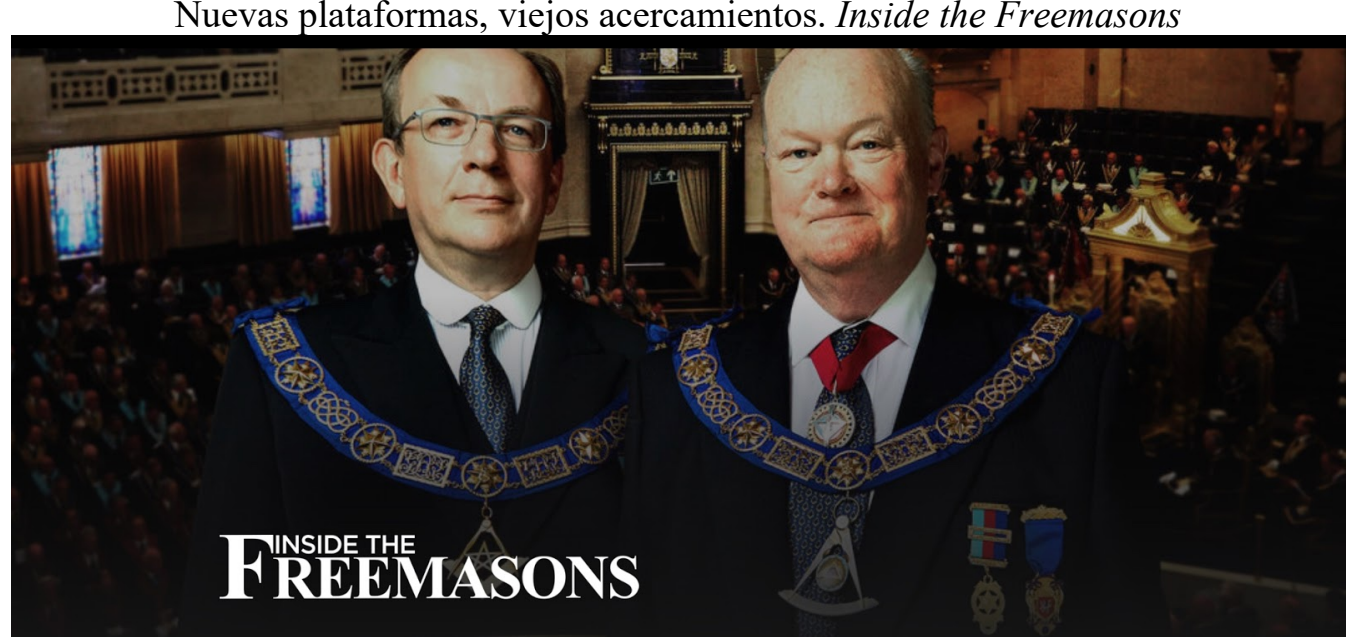

\section{Inside the Freemasons}

2017 | TV-14 | 1 Season

Explore the history and future of the Freemasons, a fraternal order steeped in both secrecy and tradition.

Fuente: Netflix.

\section{Bibliografía}

Bjelajac, David. American Art: a cultural history. Nueva Jersey: Prentice Hall, 2005.

Brunet, Lynn. "Homage to Freemasonry or indictment? The Cremaster Cycle". PAJ: A Journal of Performance and Arts 31, no. 1 (enero 2009): 98-112. https://www.mitpressjournals.org/doi/abs/10.1162/pajj.2009.31.1.98

Casebier, Allan. Film and Phenomenology: toward a realist theory of cinematic representation. Cambridge: Cambridge University Press, 1991.

Danto, Arthur C. "The Anatomy Lesson. Matthew Barney's Cremaster cycle”. The Nation, 17 de abril de 2003. https://www.thenation.com/article/anatomy-lesson/

Ditzler, Andy. "The epic ambiguity and cinematic genius of Matthew Barney's Cremaster Cycle". Artsatl, 19 de septiembre de 2010. https://artsatl.com/review-andy-ditzler-onthe-epic-ambiguity-and-cinematic-genius-of-matthew-barneys-cremaster-cycle/

Frichot, Hélene. "Matthew Barney's Cremaster Cycle revisited”. Angelaki, 20, no. 1 (2015): 55-67. https://doi.org/10.1080/0969725X.2015.1017376

Keller, Alexandra y Frazer Ward. "Matthew Barney and the Paradox of the Neo-Avant-Garde Blockbuster". Cinema Journal 45, no. 2 (invierno 2006): 3-16.

Lechte, John. "Christian Metz". Fifty Key Contemporary Thinkers. Londres: Routledge, 1995, 77-81. 
Mosley, Michael Josiah. "Another look at Heideggerian Cinema: cinematic excess, Antonioni's Dead Time and the film-photographic image as copy". Film-Philosophy 22, no. 3, $\quad$ (octubre 2018): 364-383. https://www.euppublishing.com/doi/full/10.3366/film.2018.0085

Tseng, Chiao-I y John A. Bateman. "Cohesion in Comics and Graphic Novels: an empirical comparative approach to transmedia adaptation in "City of Glass"'. Adaptation 11, no. 2 (agosto 2018): 122-143. https://doi.org/10.1093/adaptation/apx027

Winters, Ben. "The Non-Diegetic Fallacy: film, music and narrative space". Music and Letters 91, no. 2, (mayo 2010): 224-244. https://doi.org/10.1093/ml/gcq019

Žižek, Slavoj. Enjoy your Symptom! Nueva York: Routledge, 2008. 